\title{
P-DELTA EFFECTS IN MEDIUM HEIGHT MOMENT RESISTING STEEL FRAMES UNDER SEISMIC LOADING
}

\author{
J. A. Tjondro', P. J. Moss ${ }^{1}$ and A. J. Carr'
}

\begin{abstract}
An analytical investigation of the P-A effects in medium height steel moment resisting frames excited by selected earthquake motions is reported.

The frames with various design drifts and fundamental natural periods of free vibration were designed according to the loadings provisions for New Zealand's highest seismic risk zone (Wellington) of the Draft Code of Practice for General structural Design and Design Loading for Buildings, DZ4203 [10] as issued as a "Draft for Comment" in May $1986^{2}$.

The effect of strength degradation was investigated. Dynamic magnification factors for the member forces and displacement were also observed. Limits for the maximum plastic hinge rotation, inelastic drift, displacement magnification and prediction of maximum plastic hinge rotation based on the inter storey drift are suggested.
\end{abstract}

\section{INTRODUCTION}

Many previous investigations of $P-\Delta$ effects have indicated that the combination of large gravity loads and lateral displacement, especially in medium to high rise buildings, could cause this second order effect to become significant. In these investigations, the level of significance of the $P-\Delta$ effect has been expressed in terms such as stability indices, drift indices and the ratio of base shear to total mass. When the P- $\Delta$ effect becomes significant, consideration must be given to the large increases in displacement, curvature ductility, plastic hinge rotation and drift in order to maintain the stability and serviceability of the structures.

There are many different approaches to solving for $P-\Delta$ effects. In static analyses the increase of secondary moment can be taken into account as the product of relative inter-storey displacement and the vertical force. In dynamic time-history analyses the effect of changing coordinates must be taken into account in every step of the time-history analysis.

For static analyses, the use of a drift limit and stability index at a certain level of loading as was done in a previous study $[3,10]$ can enable the effect of $P-\Delta$ to be dealt with in a practical and simple way. The complexity of $P-\Delta$ effects in dynamic

1 Department of Civil Engineering, University of Canterbury, christchurch, New Zealand time-history analyses arise because of the characteristics and the intensities of different earthquakes and structural properties of the materials.

In this study, thirteen two-bay steel moment resisting frames were designed for various "design drifts" (see the later section on the Seismic Design and Analysis of the Frames) and fundamental natural periods of free vibration, based on the DZ4203's equivalent static approach with a basic seismic acceleration coefficient for Wellington [10]. The behaviour of the frames has been investigated by inelastic timehistory analyses using five different earthquake records.

Relationships between the results of the equivalent static analysis and dynamic timehistory analysis were derived in order to convert the inelastic time-history analysis to the static analysis based on DZ4203 since dynamic time-history analyses are expensive to carry out. Satisfactory design drift limits are recommended and the influence of drift limitations on plastic hinge rotation and on designing the frame lateral stiffness are also described. The influence of the PDelta effect on ductilities and plastic hinge rotations are discussed elsewhere $[13,14]$.

2 Subsequent to the submission of comment on this draft code, there has been a second draft for comment together with several revisions. This paper does not address the variations that have been put forward in these later documents. 


\section{PREVIOUS STUDIES RELATED TO P-DELTA EFFECTS}

Paulay [12] discussed the probable effect of P- $\Delta$ moments on inelastic dynamic frame response for reinforced concrete structures. It was suggested that if the strength demand due to the P- $\Delta$ effect exceeds $15 \%$ of the ideal lateral load carrying capacity of a sub-frame, the strength demand should be increased. The P-A effect should be considered by evaluating the stability index from the expression:

$$
Q_{r}=W_{t r} \cdot \delta /\left(\Sigma M_{i}-W_{t r} \cdot \delta\right) .
$$

By expressing the storey drift, $\delta$, in terms of the average slope of the frame (i.e. $\left.\Delta_{u} / H\right)$, the average of the storey heights above and below the floor under consideration, and a suitable displacement magnification factor, $\lambda$, which relates the storey drift to the average slope of the frame, the expression for $Q_{r}$ becomes [12]:

$$
Q_{r}=\lambda \cdot\left[\left(I_{c} \cdot W_{t r} \cdot \Delta_{u}\right) /\left(H \Sigma M_{i}-\lambda \cdot I_{c} \cdot W_{t r} \cdot \Delta_{u}\right)\right]
$$

where $Q_{r}=$ stability index with reference to floor $r$

$\lambda=$ displacement magnification factor which should be taken as $2.0,2.4$ and 3.0 in seismic zones $\mathrm{A}, \mathrm{B}$ and $\mathrm{C}$ respectively. (The zones referred to were those of NZS4203 [9]).

$I_{c}=$ average storey height

$\mathrm{w}_{\mathrm{tr}}=$ total gravity load considered at floor $r$

$\Delta_{u}=$ maximum displacement at roof level

$\mathrm{H}=$ total height of frame

$\mathbf{M}_{\mathbf{i}}=$ ideal moment capacity of an individual beam plastic hinge at floor $r$

Andrews [1] discussed lateral flexibility and displacement ductility controls to ensure that the frame $\mathrm{P}-\Delta$ effect never becomes significant and could be ignored. It was recommended that deflection control provided an efficient, acceptable and certain means of limiting $P-\Delta$ effects to a tolerable level. The current value of drift limit at 0.01 for zone $A$ was maintained and new limits of 0.008 and 0.006 for zones $B$ and $C$ were recommended.

Moss and carr [3], using a dynamic timehistory analysis program for inelastic frame structures, investigated the response of several concrete frames with different stiffness properties and strength. It was found that with a drift limit of $0.01, P-\Delta$ effects can be ignored. For greater interstorey drifts the effect of gravity load leads to a rapidly increasing augmentation of the inter-storey drift and exceeds the ability of the structures to provide the necessary ductility. Increasing the strength for inelastic frames, rather than stiffness, offers the most effective control of increase in displacement.

Montgomery [6] found in his study that the $P-\Delta$ effect has a significant influence when the ratio of the total weight to base shear is greater than or equal to 10 , or the maximum storey drift is more than twice the storey drift at yield.

\section{SEISMIC DESIGN AND ANALYSIS OF FRAMES}

The frames were designed according to NZS3404 [8] to resist the loads specified by DZ4203 [10] with the new basic seismic acceleration spectrum which seems slightly stronger than El Centro 1940. Calculation of the base shear is based on:

$$
\begin{aligned}
& \mathrm{V}=\mathrm{C} \cdot \mathrm{W}_{\mathrm{t}} \\
& \mathrm{C}=\mathrm{C}_{\mu} \cdot \mathrm{R} \cdot \mathrm{z}
\end{aligned}
$$

where: $\quad C_{\mu}=$ basic seismic coefficient varying with $\mu$

$\mathrm{z}$ = Zone factor,

for seismic risk zone $A=0.85$

$\mathrm{R}=$ risk factor $=1.0$

3.0

$\mathrm{R}$
$\mu$

A ductility factor of 3.0 for steel moment resisting frames was suggested by the New Zealand Study Group for steel structures [15]. The six, twelve and eighteen-storey frames were designed with various design drift limits. The "design drift limit" was defined as the structural ductility factor, $\mu$, times the elastic drift from the equivalent static load, as a prediction of the inelastic drift under seismic loading [10].

The following load combinations were used for design:

$$
\begin{aligned}
& 1.4 \mathrm{D} \\
& 1.2 \mathrm{D}+1.6 \mathrm{~L}_{\mathrm{r}} \\
& 1.2 \mathrm{D}+1.2 \mathrm{~L}_{\mathrm{s}}+\mathrm{E} \\
& 0.9 \mathrm{D}+\mathrm{E}
\end{aligned}
$$

The weight of the floor slab was taken as $2.7 \mathrm{kPa}$ with an allowance of $0.5 \mathrm{kPa}$ for finishing and combined with self weight of the member gave a total uniform dead load, $D$, of $23.4 \mathrm{kN} / \mathrm{m}$. Live load for general use, $\mathrm{L}_{u}$, was $2.5 \mathrm{kPa}$, and the serviceability live load, $L_{s}$, was $0.8 \mathrm{kPa}$. $L_{r}$ refers to the reduced live load and $E$ to the earthquake load. Typical frames are shown in Figure 1.

steel frames, by their very nature, are usually more flexible and therefore have longer fundamental periods than concrete frames. This gives an advantage in reducing the response of the frames under certain types of earthquake, while in other cases they could experience their peak response from an earthquake with a long period. The critical combination of design load for medium to high rise buildings is usually the combination of gravity load with horizontal earthquake load or with the wind load. Frames are expected to survive with repairable structural damage at the design earthquake load.

To achieve low design drifts, some of the above loading combinations are non-critical; this design excluded consideration of the load combinations with wind load. To maintain column stability, the ratio of axial force to compression yield force, $P / P_{y}$, was considered to be less than 0.4 a's suggested by de Buen [4] or $P / P_{y}$ less than 0.5 as suggested by the New Zealand study Group for steel structures [2]. 

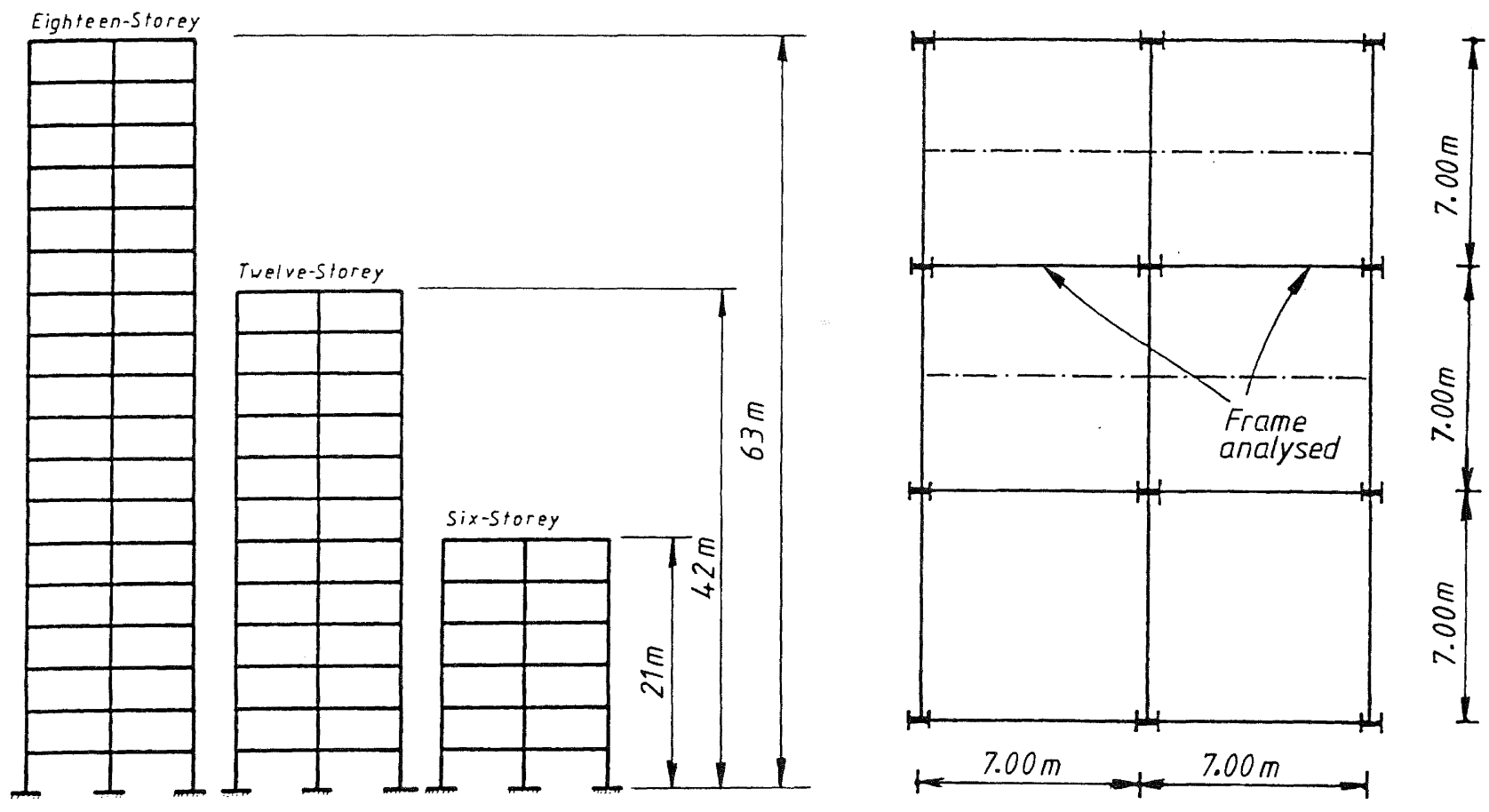

\section{FIGURE 1. (LEFT) SIX,TWELVE AND EIGHTEEN STOREY STEEL MOMENT-RESISTING FRAMES \\ (RIGHT) TYPICAL PLAN VIEW \\ All frames have the same storey height of $3.5 \mathrm{~m}$.}

TABLE 1 DESIGN DRIFT8, PERIODS AND DESIGN BASE SHEARS FOR THE FRAMES ANALYSED

\begin{tabular}{|c|c|c|c|c|}
\hline & $\begin{array}{c}\text { Frame } \\
\text { no. }\end{array}$ & Design Drift & $\begin{array}{c}\text { Period } \\
(\mathrm{sec} .)\end{array}$ & $\begin{array}{c}\text { Design Base Shear } \\
(\mathrm{KN})\end{array}$ \\
\hline 6 storey & 1 & 0.0131 & 1.143 & 348 \\
frame & 2 & 0.0139 & 1.270 & 310 \\
& 3 & 0.0168 & 1.474 & 272 \\
& 4 & 0.0188 & 1.581 & 255 \\
12 storey & 5 & 0.0105 & 1.774 & 460 \\
frame & 6 & 0.0112 & 1.866 & 426 \\
& 7 & 0.0132 & 2.230 & 376 \\
& 8 & 0.0150 & 2.409 & 356 \\
& 9 & 0.0167 & 2.658 & 333 \\
18 storey & 10 & 0.0123 & 2.792 & 487 \\
frame & 11 & 0.0135 & 2.959 & 466 \\
& 12 & 0.0152 & 3.237 & 433 \\
& 13 & 0.0162 & 3.618 & 387 \\
& & & & \\
\hline
\end{tabular}

Flange and web slenderness ratios of beams and columns were chosen within the limits suggested by the New Zealand Study Group for Steel structures [2].

The fundamental period and design base shear for the frames having different design drifts are given in Table 1.

\section{Members and Joint Connections}

Joint connections were modelled as rigid joints with the rigid foundation as a fixed support. Structural components or members were modelled by a prismatic member with an inelastic spring hinge at each end. The end of the member incorporates a rigid end-block which was taken as a half of the column or beam depth to approximately match the real structure. 


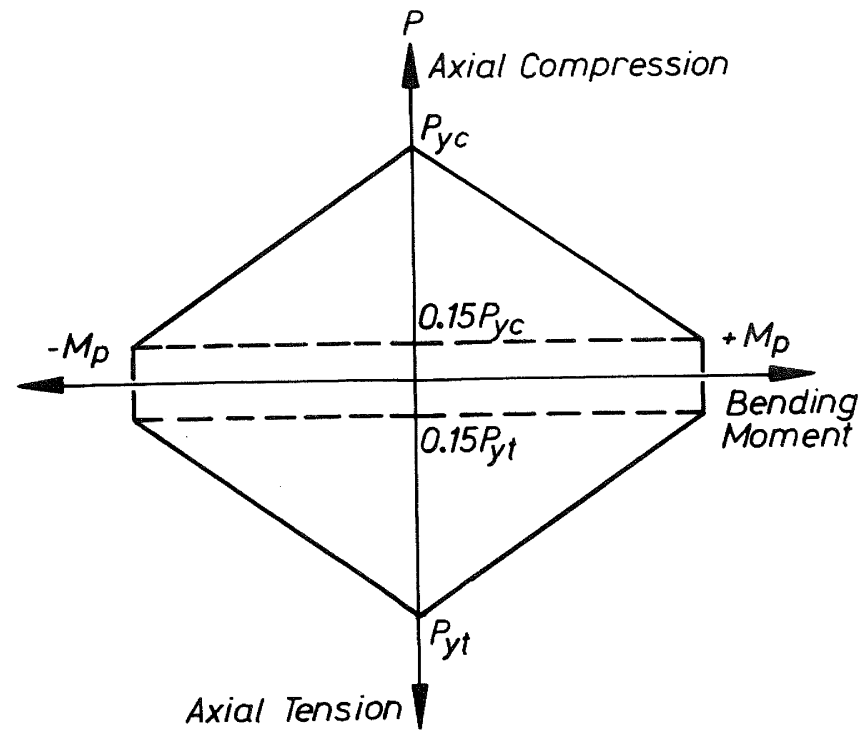

FIGURE 2. MOKENT-AXIAL LOAD INTERACTION DIAGRAY

The floor was modelled as rigid in its own plane. Uniform gravity load was applied to the beams as fixed end moments and shear forces at the end nodes ignoring the rigid end-block lengths.

\section{Moment-Curvature Relationship}

A bi-linear elastic moment curvature relationship was chosen for the columns, while an elasto-plastic model was used for the beams. The elasto-plastic model was assumed to be adequate for steel beams in moment resisting frames with low axial force and wide strain range before reaching strain-hardening.

Previous studies by otani [11], Carr, Moss and Buchanan [7] and others using different hysteresis rules showed that the response of the structures is generally insensitive to the shapes of the hysteresis loop.

\section{Moment-Axial Load Interaction}

An approximation was used in the momentaxial interaction diagram as shown in Fig.2. The effect of axial tension or compression [2] on the bending moment capacity of the member about the major principal axis are defined by:

$$
\begin{aligned}
& \text { (i ) } \mathrm{P} / \mathrm{P}_{\mathrm{y}}<0.15 \quad \mathrm{M} / \mathrm{M}_{\mathrm{P}}<1.0 \\
& \text { (ii) } P / P_{y}^{y}>0.15 \quad P / P_{y}+M /\left(1.18 M_{p}\right)<1.0
\end{aligned}
$$

\section{Damping}

In order to ensure that all modes are subcritically damped when using a proportionally damped model, a value of $5 \%$ of critical damping for the steel frames was assumed and applied as follows:

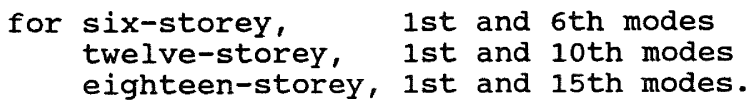

\section{Earthquake Acceleration Records}

Five different earthquake acceleration records were chosen to study the effects of $P-\Delta$ and the general behaviour of the frames designed to DZ4203 loading criteria under different intensities and characteristics of earthquake motions. The designed frames with various design drifts and fundamental periods were analysed under the following earthquakes:

- Bucharest N-S, 1977 (corrected)

- El Centro N-S, 1940 (corrected)

- Artificial NZ4203 for seismic zone A

- Pacoima Dam S14W, 1971

- Parkfield N65E, 1966

The El Centro 1940 and Artificial NZ4203/A were used as the design level earthquakes for New Zealand seismic zone A. Bucharest, Parkfield and Pacoima Dam were used to gain a complete understanding of the response of the frames under severe earthquakes.

\section{INELASTIC TIME HISTORY ANALYSES}

Investigation of $P-\Delta$ effects from the results of the inelastic time-history analyses has been done by comparing the standard analyses and the analyses with the inclusion of $P-\Delta$ effects for the maximum value of: storey displacements, plastic hinge rotation and inter-storey drift. The inter-storey drift was observed and expressed in terms of a drift index based on the inter-storey height, $h$. Other influences of $P-\Delta$ effects on curvature ductilities, axial load and column moment magnification factors, base shear and column shear forces are described in reference 14.

For the twelve-storey steel moment resisting frames, the axial force due to gravity load in the lower part of the frame is almost twice of that in the lower part of sixstorey moment resisting frames. The fundamental periods of the frames are such that they show significant response from the earthquakes. Because the gravity load is greater, the effect of secondary moment will be more important for these twelve-storey frames compared to the six-storey frames with the same design drifts.

The eighteen-storey steel moment resisting frames had a range of natural periods between 2.8 and 3.6 seconds. The axial compression force was mainly due to the gravity load with the contribution of earthquake load on the axial force being small compared to the gravity load. Seismic coefficients in these eighteen-storey frames were quite low owing to the long fundamental natural periods. It is probable that wind loading would be more critical than earthquake loading.

\section{INELASTIC TIME-HISTORY ANALYSIS RESULTS}

\section{Displacements}

\section{(a) 6 storey frames}

As shown in Fig. 3, during the El centro 1940 earthquake, all of the maximum top 

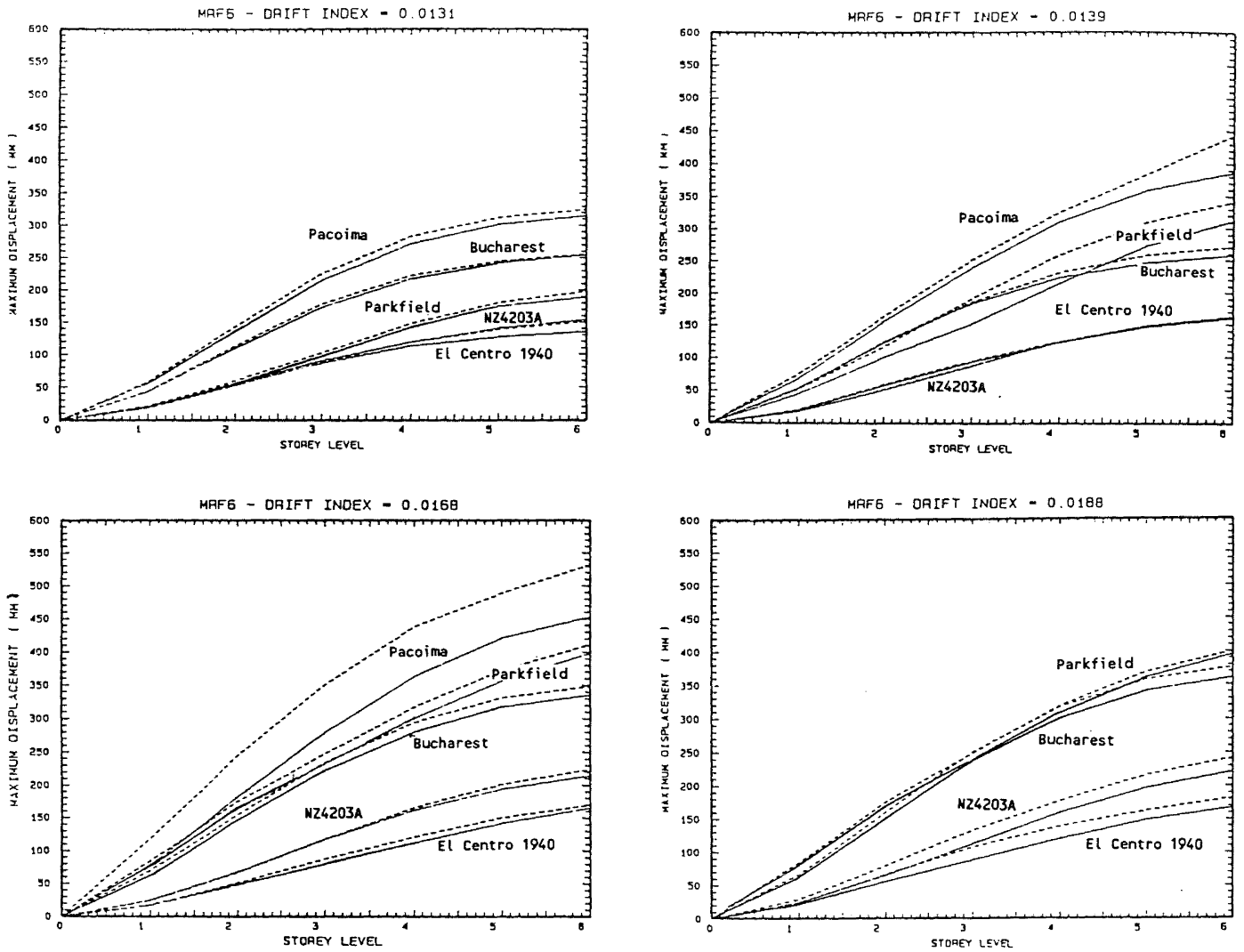

FIGURE 3. BIX STOREY FRAMES: COMPARISON OF MAXIMUM FLOOR DISPLACEMENTS BETWEEN STANDARD ANALYSES (-) AND P-A ANALYSES $(--\infty$
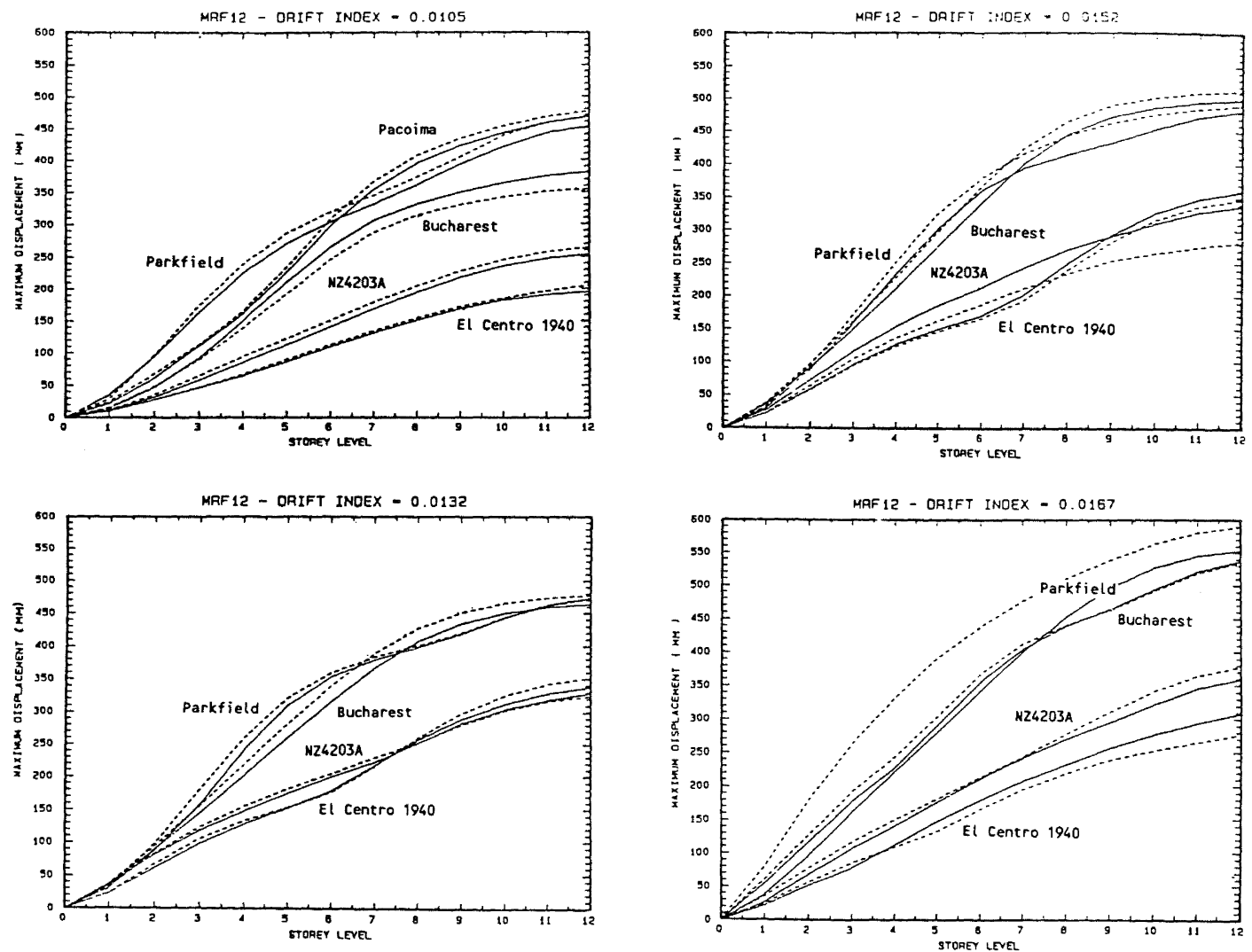

FIGURE 4. TWELVE STOREY FRAMES: COMPARISON OF MAXIMUM FLOOR DISPLACEMENTS BETWEEN STANDARD ANALYSES $(\longrightarrow)$ AND P- $\triangle$ ANALYSES $(---)$ 
floor displacements for frames with a design drift range of $0.0131 \mathrm{~h}-0.0188 \mathrm{~h}$ satisfied the requirement of the maximum top floor displacement being less than $0.01 \mathrm{H}(210 \mathrm{~mm})$. The Artificial NZ4203/A gave a similar response to El Centro 1940 for low design drifts of $0.0131 \mathrm{~h}-0.0139 \mathrm{~h}$. In these figures, standard analyses are drawn with continous lines and $P-\Delta$ with dashed lines. The Artificial NZ4203/A earthquake with higher drifts of $0.0168 \mathrm{~h}-0.0188 \mathrm{~h}$ produced higher response than El centro 1940. This is understandable because a higher drift means that the structure has a longer fundamental period and is more flexible and it responds more to a longer spectral period earthquake such as the Artificial NZ4203/A.

The inclusion of $P-\Delta$ effects for design drifts of $0.0131 \mathrm{~h}-0.0168 \mathrm{~h}$ for these two earthquake records, which are New Zealand design level earthquakes shows an increase of between 1-4\% over the standard analysis. At a design drift index of 0.0188 the difference is about 8-10\%.

The maximum top floor displacement during the Parkfield earthquake at a design drift of $0.0131 \mathrm{~h}$ is below $0.01 \mathrm{H}$ and less than for the Bucharest record. This phenomena can be explained by the characteristics of the Bucharest record which has a longer spectral period than Parkfield. For frames with design drifts of $0.0139 \mathrm{~h}-0.0188 \mathrm{~h}$, displacement responses under Parkfield are higher than Bucharest. Significant $P-\Delta$ effects appear for a design drift of $0.0139 \mathrm{~h}$ during the Parkfield earthquake.

The Bucharest earthquake with a long period and two strong pulses at approximately 3.5 seconds did not show significant $P-\Delta$ effect for this six-storey frame. A difference of only $5 \%$ was found between the two analyses. The maximum top floor displacement at a design drift of $0.0188 \mathrm{~h}$ was $0.018 \mathrm{H}$, which seems unacceptably high.

The difference between the maximum displacement response for the standard and $P-\Delta$ analyses for a design drift index of 0.0131 during Pacoima earthquake is negligible, but the rest of the other three frames showed significant influence of $P-\Delta$ effects because the intensity of this earthquake is very strong. At a drift of $0.0168 \mathrm{~h}$ the maximum top floor displacement increases nearly $20 \%$ when compared to the standard analysis. A column storey mechanism occured in the frame with a design drift of $0.0188 \mathrm{~h}$ under Pacoima Dam earthquake.

\section{(b) 12 storey frames}

During the El Centro 1940 and Artificial NZ4203/A earthquakes all of the maximum top floor displacements of the frames with design drift $0.0105 \mathrm{~h}-0.0167 \mathrm{~h}$ were within the limit of $0.01 \mathrm{H}(420 \mathrm{~mm})$, as shown in Fig. 4 . At the design drift of $0.0167 \mathrm{~h}$ the inclusion of the P- $\Delta$ effect under the El Centro 1940 record reduced the response by $10 \%$ and for Frame no.8 under the Artificial NZ4203/A record this second order effect reduced the maximum top floor displacement by $30 \%$. In the other three frames, the inclusion of $P-\Delta$ had a negligible effect on the response, the only factor of interest was whether the maximum displacements exceeded the serviceability limit or not.

The Bucharest earthquake gave a maximum top floor displacement of more than $0.01 \mathrm{H}$ for design drift greater than $0.0132 \mathrm{~h}$ and the inclusion of $\mathrm{P}-\Delta$ effect was negligible. The response was reduced by $7 \%$ with the $\mathrm{P}-\Delta$ effect at a design drift of $0.0105 \mathrm{~h}$. At higher design drifts the maximum displacement from the Bucharest earthquake gave a reasonably good agreement to the response of the Parkfield earthquake.

The Parkfield earthquake showed significant increases in the floor displacements in the lower to middle height of the storey levels of Frame no.10, for a design drift of $0.0167 \mathrm{~h}$. All of the maximum top floor displacements during the Parkfield record exceeded the limit of $420 \mathrm{~mm}$, but still showed no significant influence of $P-\Delta$ for design drifts of $0.0105 \mathrm{~h}-0.0152 \mathrm{~h}$.

The Pacoima Dam earthquake gave all of the maximum top floor displacements greater than $0.01 \mathrm{H}$ and significant influence of the $\mathrm{P}-\Delta$ effect was found at a design drift of $0.0168 \mathrm{~h}$. Negligible influence of the $P-\Delta$ effect was found at a design drift lower than $0.0132 \mathrm{~h}$. At a design drift of $0.0105 \mathrm{~h}$ the maximum top floor displacement was 477 $\mathrm{mm}$, which seems acceptable for a very severe earthquake.

\section{(c) 18 storey frames}

The maximum top floor displacements for the various frames having design drift indices of 0.0123 to 0.0162 did not exceed $0.01 \mathrm{H}$ or $620 \mathrm{~mm}$, except under the Pacoima Dam record.

During the El Centro 1940 earthquake, frames with higher design drift indices had a smaller response. When the natural fundamental period became lower such as in Frame no. 10, the response of the frame increased as shown in Fig. 5. The increase of the maximum top floor displacement was about $10 \%$. This is in contrast to the six and twelve-storey frames where the lesser response was related to the lower interstorey drift.

Frame no.13 with Artificial NZ4203/A record, gave a strong response which was very close to that of the Bucharest and Parkfield records. Under this artificial record, the maximum top floor displacement increased by $20 \%$ for the analysis with the inclusion of the $P-\Delta$ effect. At a design drift index of 0.0152 the response which included $P-\Delta$ effect was reduced. The other two frames with design drift indices of 0.0123 and 0.0135 gave similar responses for the displacements as El Centro 1940 earthquake and the $P-\Delta$ effect was not significant.

The behaviour under the Bucharest and Parkfield excitations was not affected by the inclusion of the $P-\Delta$ effect. The similar responses for the maximum top floor displacements are shown in Fig. 5. 

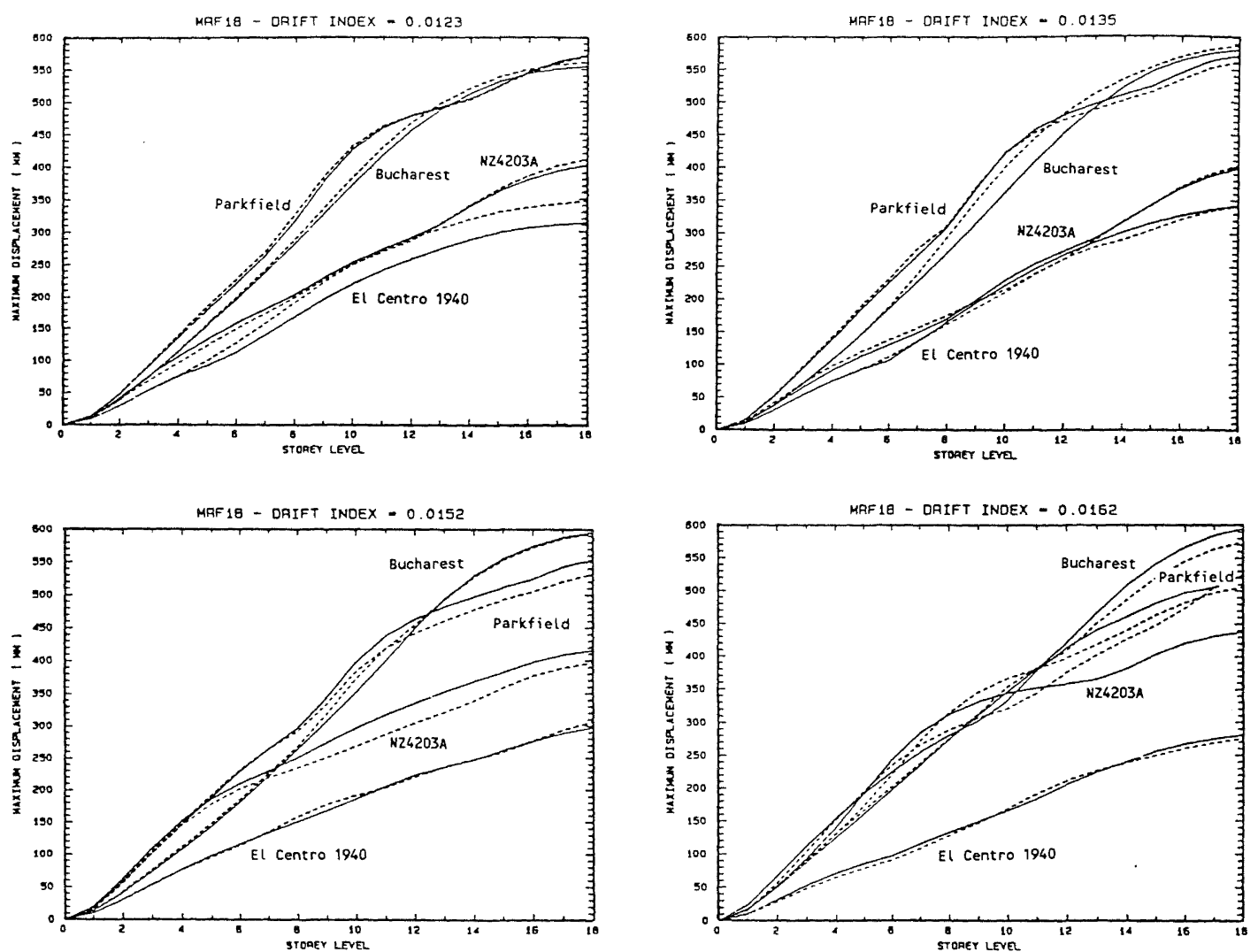

FIGURE 5. EIGHTEEN STOREY FRAMES: COMPARISON OF MAXIMUM FLOOR DISPLACEMENTS BETWEEN STANDARD ANALYSES (-) AND P-A ANALYSES $(--$,
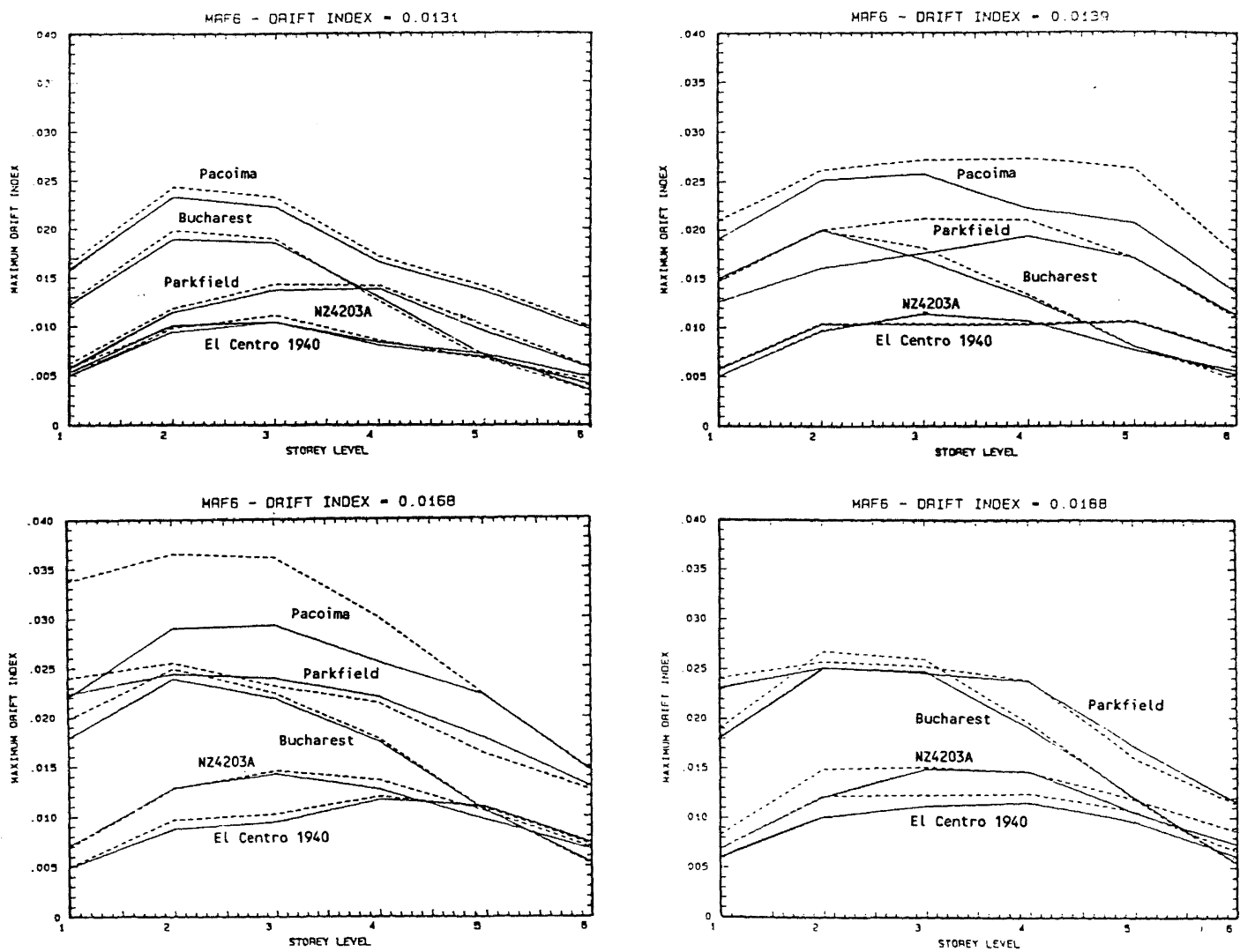

FIGURE 6. SIX STOREY FRAMES: COMPARISON OF MAXIMUM INTER-STOREY DRIFTS BETWEEN STANDARD ANALYSES $(-)$ AND P-A ANALYSES $(---)$ 

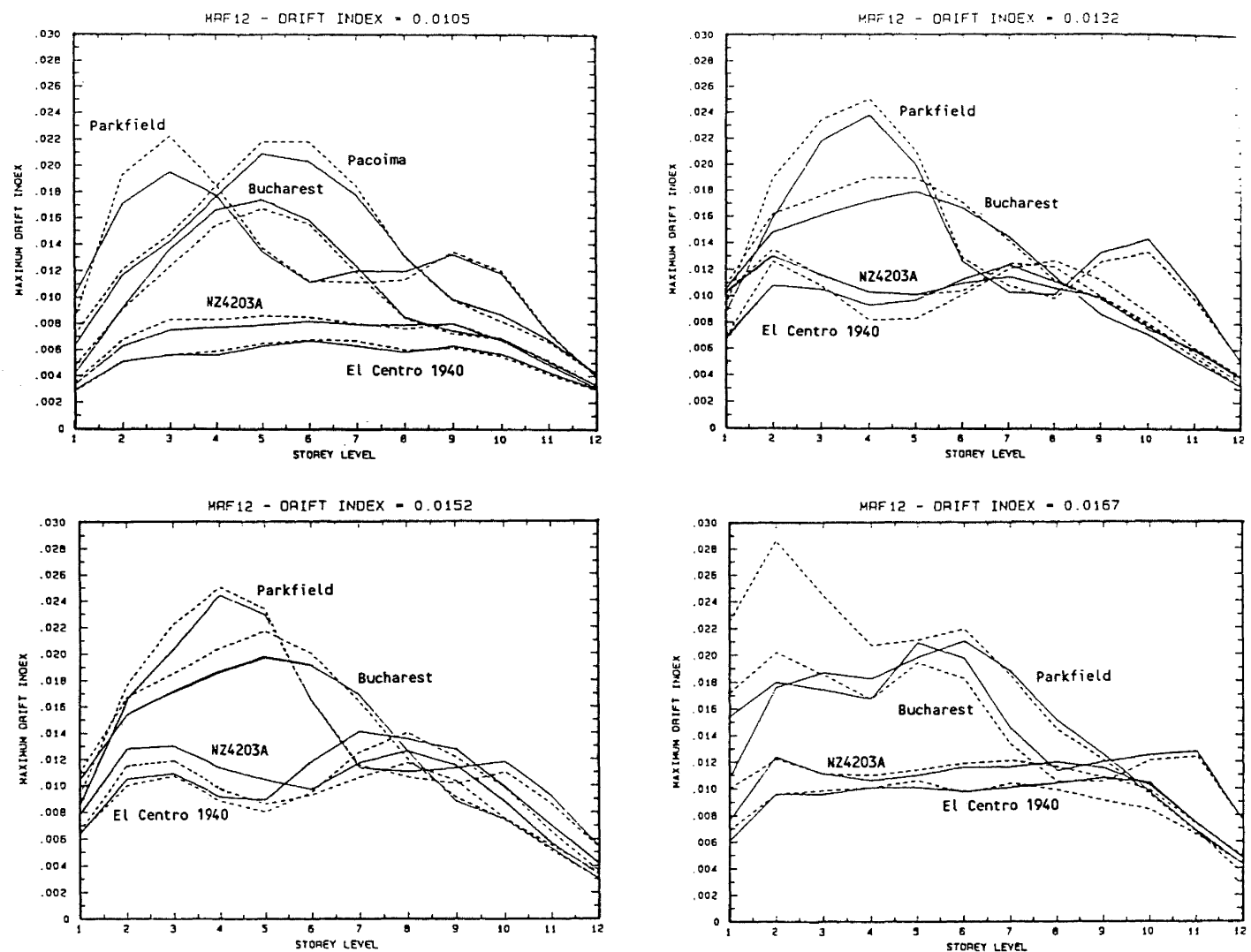

FIGURE 7. TWELVE STOREY FRAMES: COMPARISON OF MAXIMUM INTER-STOREY DRIFTS

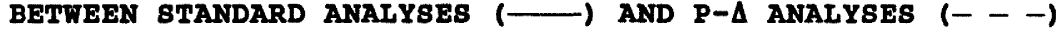
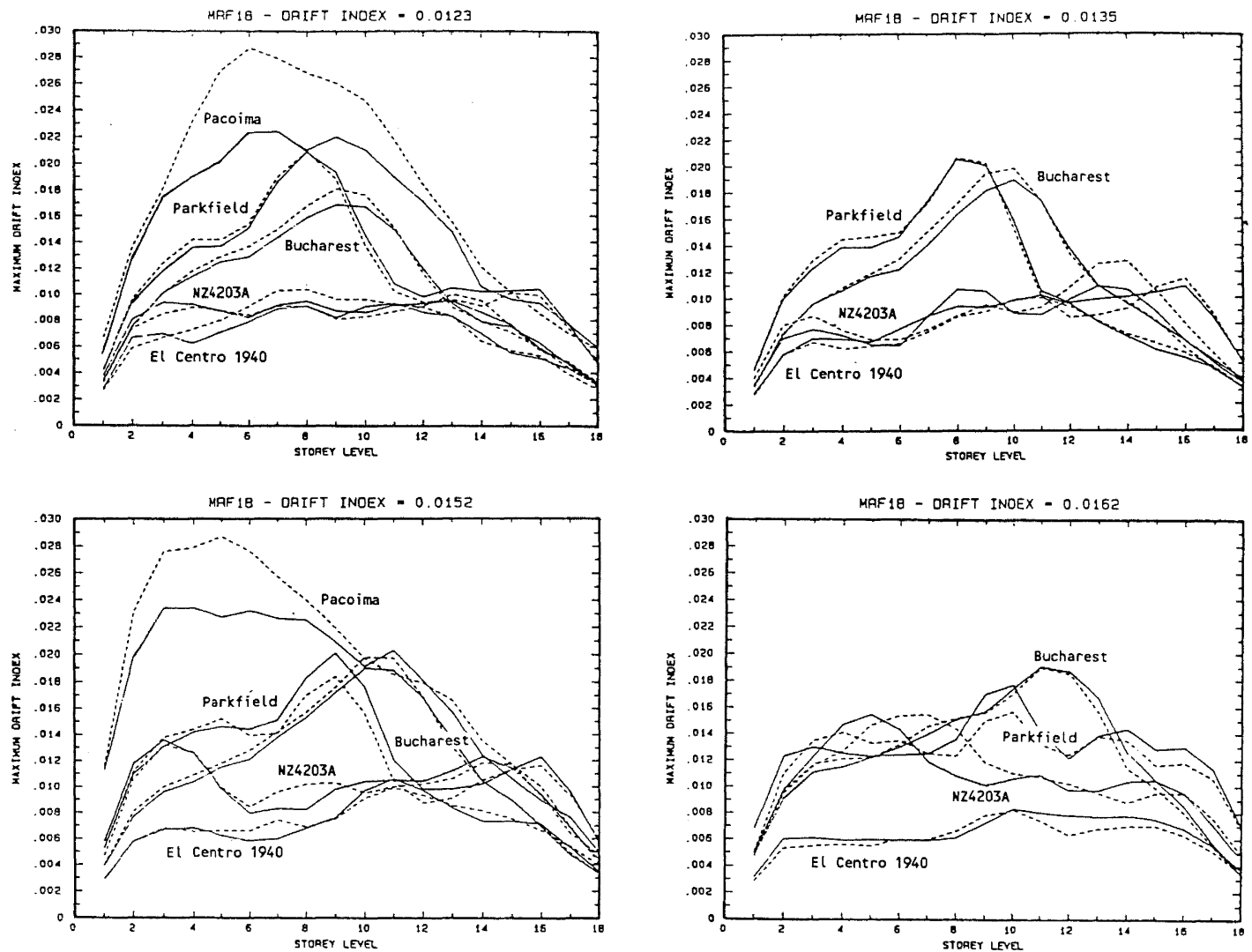

FIGURE 8. EIGHTEEN STOREY FRAMES: COMPARISON OF MAXIMUM INTER-STOREY DRIFTS BETWEEN STANDARD ANALYSES $(\longrightarrow)$ AND P- $\longrightarrow$ ANALYSES $(--$, 


\section{Inelastic Inter-storey Drift}

\section{(a) 6 storey frames}

The response of the frame with a design drift of $0.0131 \mathrm{~h}$ is satisfactory for all of the earthquake records, (see Fig. 6). El Centro 1940 and Artificial NZ4203/A gave close results for maximum inter-storey drift, (storey level no. in the graphs indicates inelastic drift index between that level and one level below), with maximum inelastic drift of $0.01 \mathrm{~h}$. The inclusion of $\mathrm{P}-\Delta$ in the Frame no. 1 has a negligible effect. Under strong earthquakes such as Pacoima Dam, the value of 0.025 times the storey height for inelastic drift seems reasonable considering the intensity of this earthquake.

At higher design drifts, the response due to the Artificial NZ4203/A was higher than that due to the El Centro 1940 record. More than a $10 \%$ increase in inter-storey drift with inclusion of $\mathrm{P}-\Delta$ at frames with a design drift greater than $0.0139 \mathrm{~h}$, and $20 \%$ increase for design drift of $0.0188 \mathrm{~h}$ were found. Maximum inter-storey drifts were generally critical in the middle storeys, from level one to level four.

\section{(b) 12 storey frames}

The El Centro 1940 and Artificial NZ4203/A excitations showed that the inelastic interstorey drifts were always lower than the design drift and no significant influence on the inclusion of the $\mathrm{P}-\Delta$ effect (see Fig. 7). Some results showed that the response was reduced by the second order effect for these two earthquakes.

Bucharest and Parkfield earthquakes gave a value between $0.020 \mathrm{~h}-0.025 \mathrm{~h}$ for the maximum inter-storey drift. Only for the frame with a design drift index of 0.0167 did the inclusion of the $\mathrm{P}-\Delta$ effect become significant.

The Pacoima Dam record gave a good response for frames with a design drift index lower than 0.0112 . It was shown that for inelastic drift lower than $0.022 \mathrm{~h}$ the influence of the $P-\Delta$ effect was not significant in increasing the inter-storey drift.

\section{(c) 18 storey frames}

Fig. 8 shows that the value of maximum inelastic inter-storey drift under $E I$ centro 1940 and Artificial N24203/A records was always lower than the design drift. The inelastic drift index for Frame no.13 during the El Centro 1940 earthquake was 0.0085 compared to the design value of 0.0162 .

The Parkfield and Bucharest records gave inter-storey drift indices between 0.018 and 0.021 , showing no significant influence of the P- $\Delta$ effect. The Pacoima Dam earthquake gave good behaviour if the design drift was lower than $0.0123 \mathrm{~h}$.

\section{Plastic Hinge Rotation}

\section{(a) 6 storey frames}

The plastic hinge rotations observed in the frame with a design drift of $0.0131 \mathrm{~h}$ are satisfactory; El Centro 1940 and Artificial NZ4203/A give a maximum plastic hinge rotation of 0.015 radians and the value of 0.032 radians for Pacoima Dam earthquake (see Fig. 9). The value plotted at ground level is the maximum plastic hinge rotation at the column base. No significant influence of $P-\Delta$ effects on the plastic hinge rotations in the design drift of $0.0131 \mathrm{~h}$ was observed under any of the earthquake records.

Frames having design drifts of $0.0139 \mathrm{~h}-$ $0.0168 \mathrm{~h}$ showed a significant influence of $\mathrm{P}$ $\triangle$ effects under Pacoima Dam and Parkfield records, there being more than a $20 \%$ increase over the standard analyses. A plastic hinge rotation of 0.054 radians under Pacoima Dam earthquake for a design drift of $0.0168 \mathrm{~h}$ would be unacceptable.

At a design drift of $0.0188 \mathrm{~h}$, the maximum plastic hinge rotation with inclusion of $\mathrm{P}$ $\triangle$ was increased by $15-20 \%$ under El Centro 1940 and Artificial NZ4203/A earthquakes. Surprisingly, the influence of $P-\Delta$ on the plastic hinge rotations under Parkfield and Bucharest records was negligible, although the intensities of these two earthquakes are stronger than the El Centro 1940 or the Artificial NZ4203A records.

De Buen [4] has suggested that for a steel beam a value of 0.030 radians is a conservative limit for plastic hinge rotation. The rotation capacity of steel beams in some experiments [5] is higher than 0.030 radians. However serviceability requirements may not be satisfied if the plastic hinge rotation is more than 0.030 radians.

\section{(b) 12 storey frames}

The increase of plastic hinge rotations due to the second order effect did not seem to become a problem if the rotation was below the limit of 0.030 radians (see Fig. 10). Under the El Centro 1940 and Artificial NZ4203/A earthquakes this limit was not reached by the frames with design drift indices lower than 0.0167 .

During the Bucharest and Parkfield records the values of maximum plastic hinge rotations were between $0.025-0.030$ radians with a significant influence of the $P-\Delta$ effect at design drift of $0.0167 \mathrm{~h}$.

The Pacoima Dam earthquake gave satisfactory plastic hinge rotation at a design drift lower than 0.0112 storey height.

\section{(c) 18 storey frames}

Plastic hinge rotation for all the earthquakes (see Fig. 11), except Pacoima Dam, were lower than 0.030 radians. The influence of the second order effect was not significant. Under the Pacoima Dam record, a $20 \%$ increase in maximum plastic hinge rotation occured at the design drifts of $0.0135 \mathrm{~h}$ and $0.0123 \mathrm{~h}$. 

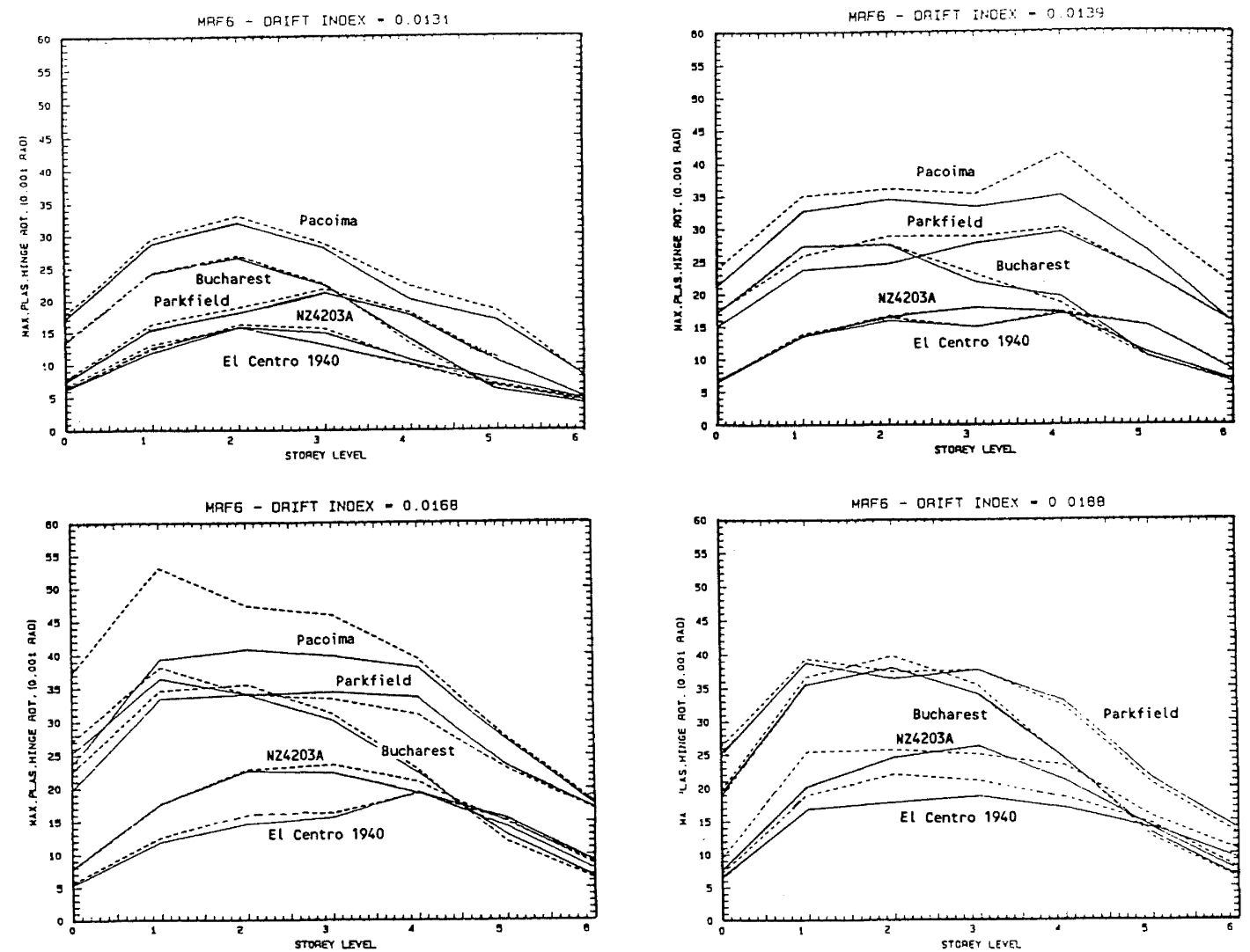

FIGURE 9. SIX STOREY FRAMES: COMPARISON OF MAXIMUM PLASTIC HINGE ROTATIONS AT THE COLUMN BASES AND FLOOR BEAMS BETWEEN STANDARD ANALYSES $(\longrightarrow$ AND P-A ANALYSES (- - -)
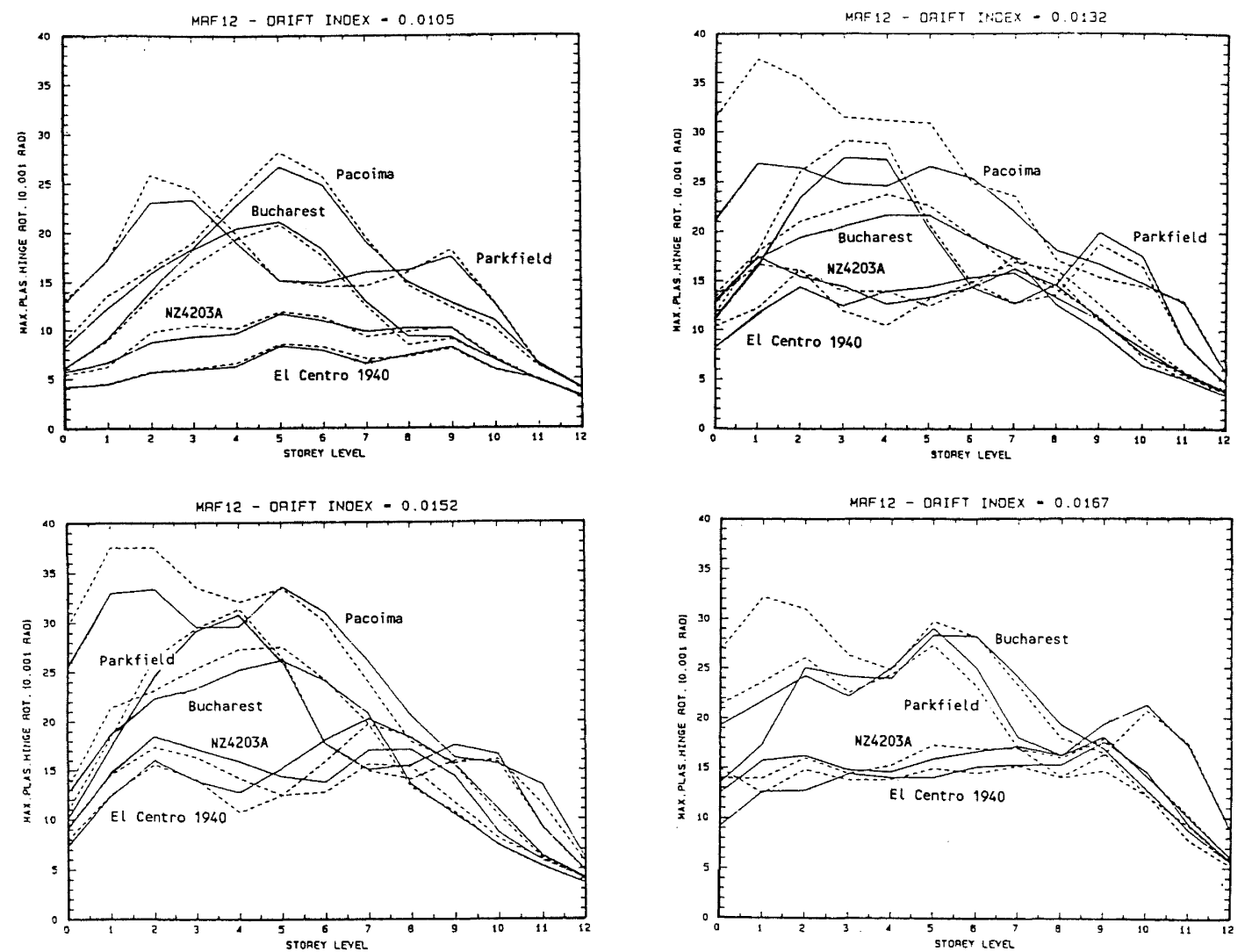

FIGURE 10. TWELVE STOREY FRAMES: COMPARISON OF MAXIMUM PLASTIC HINGE ROTATIONS AT THE COLUMN BASES AND FLOOR BEAMS BETWEEN STANDARD ANALYSES $(\longrightarrow$ AND P-A ANALYSES $(--)$, 

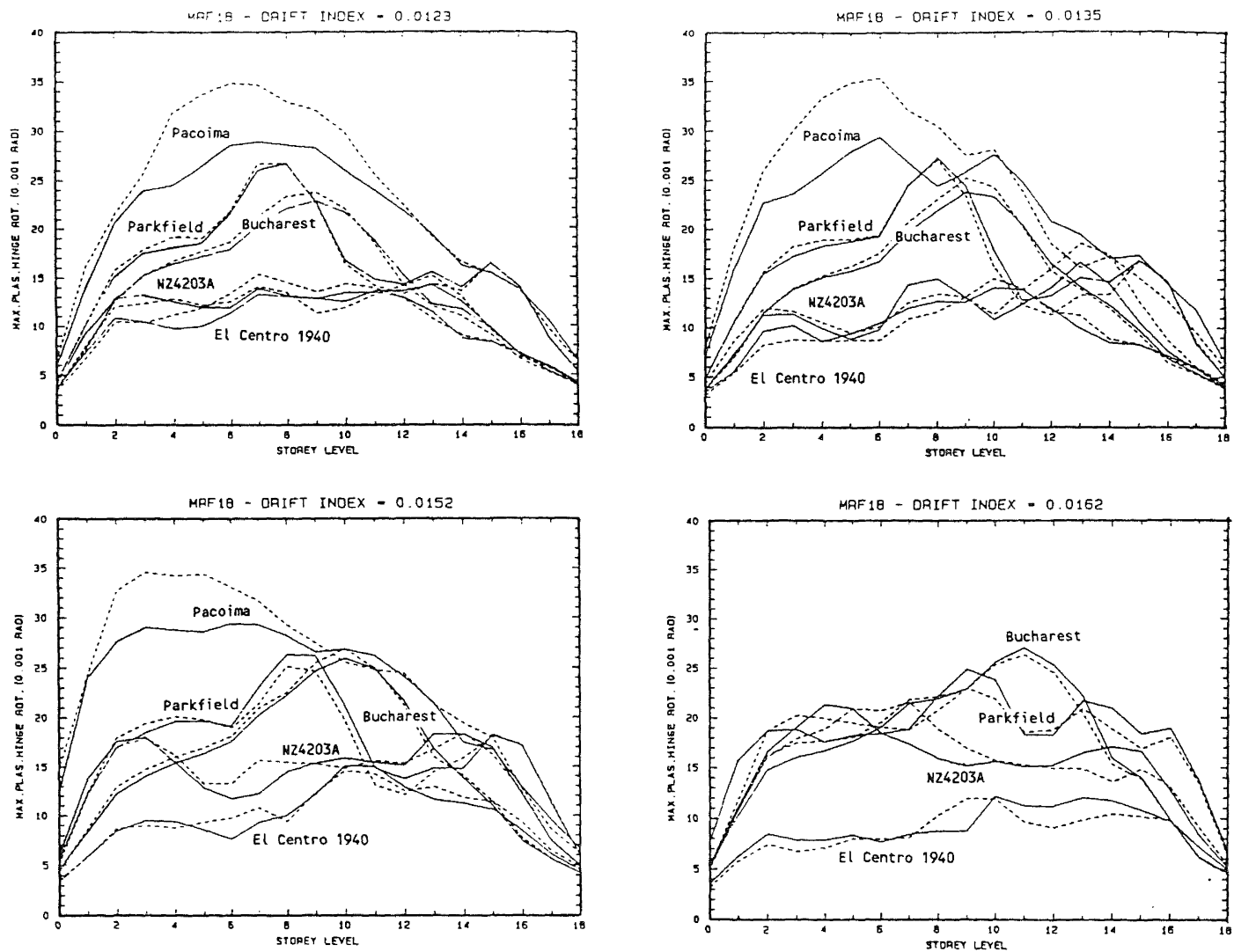

FIGURE 11. EIGHTEEN STOREY FRAMES: COMPARISON OF MAXIMUM PLASTIC HINGE ROTATIONS AT THE COLUMN BASES AND FLOOR BEAMS BETWEEN STANDARD ANALYSES (-) AND P-A ANALYSES $(---)$

\section{Drift Amplification Factor}

\section{(a) 6 storey frames}

The ratios of maximum inelastic drift to the design drift based on DZ4203 under various different earthquakes can be seen in Fig. 12 .

The amplification factor for inelastic drift under El Centro 1940 record is about 0.8 times the design drift, or 2.4 times the static drift produced by the equivalent static load. For longer periods, the value reduced from 0.79 to 0.66 times the design drift.

The Artificial NZ4203/A record gives a amplification factor slightly higher than El Centro 1940. The drift amplification factor under Bucharest and Parkfield earthquake gave close agreement, around 1.5 times the design drift or 4.5 times the equivalent static drift. Inelastic drift under Pacoima Dam earthquake is twice that of the design drift or 6 times the equivalent static drift.

\section{(b) 12 storey frames}

The Artificial NZ4203/A accelerogram indicated the same value for the maximum drift as the design drift based on DZ4203 for frames with design drifts of $0.0112 \mathrm{~h}-$ $0.0132 \mathrm{~h}$ (see Fig. 13) giving an amplification factor of 1.0 and a reduction to about 0.8 times the design drift for frames with design drifts of $0.0105 \mathrm{~h}$, $0.0152 \mathrm{~h}$ and $0.0167 \mathrm{~h}$. The El Centro 1940 record gave values of 0.6 for frames with design drift indices of 0.0105 and 0.0167 , and the reduction factor of 0.8 for design drift indices of $0.0112-0.0152$. These two earthquakes generally gave a reduction to 0.8 times the design drift or 2.4 times drift from the equivalent static analysis. The magnification factor of 2.4 was close to the displacement magnification factor of 2.0 for zone A given by Paulay [12] which : was determined from deflected shapes of elastic and inelastic frames.

At a design drift of $0.0105 \mathrm{~h}$, both Pacoima Dam and Parkfield earthquakes gave an amplification factor of 2.1 to the DZ4203 design drift of 6.3 times the drift from the equivalent static analysis. The Bucharest record gave an amplification factor of approximately 1.50 to the design drift or 4.50 times the elastic drift.

The amplification factor decreased as the drift limit became higher and increased as the magnitudes of the earthquakes became larger.

\section{(c) 18 storey frames}

The drift amplification factors under the Parkfield, Bucharest and El Centro 1940 


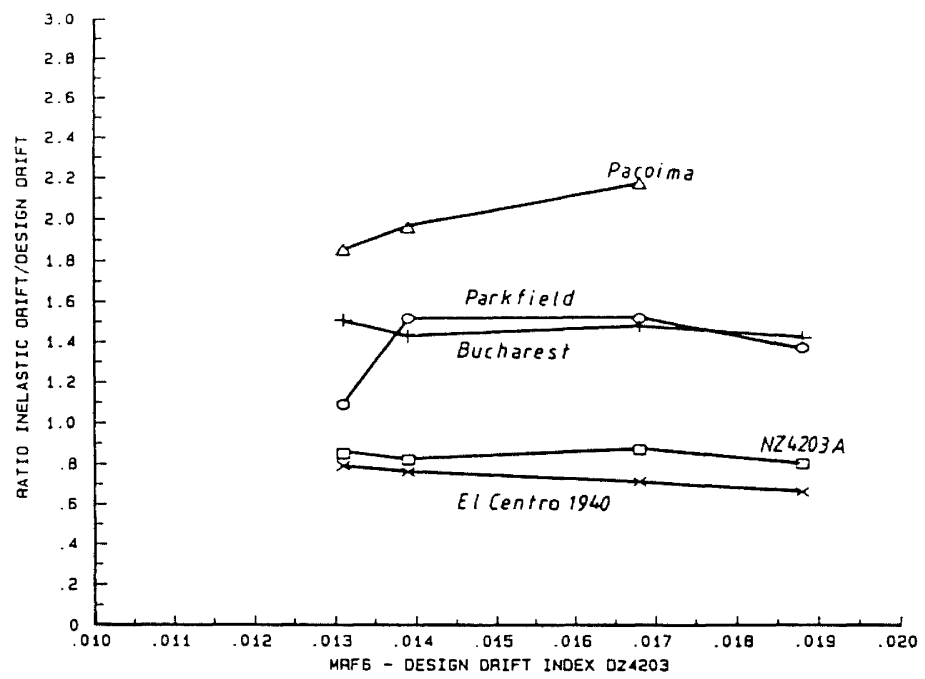

FIGURE 12. SIX STOREY FRAMES: INELASTIC DRIFT AMPLIFICATION FACTOR FOR VARIOUS EARTHQUAKES

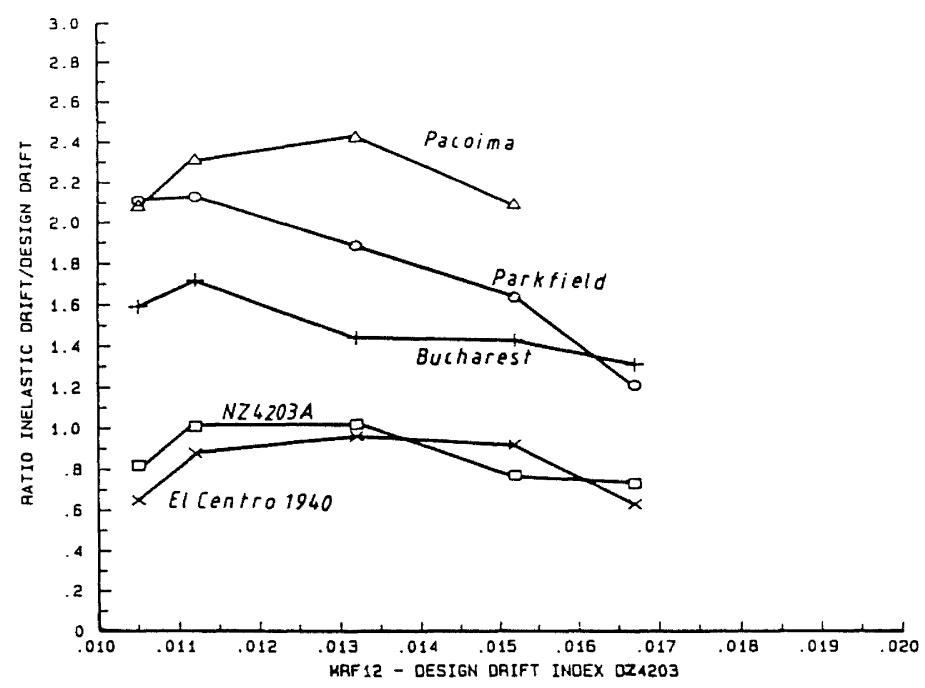

FIGURE 13. TWELVE STOREY FRAMES: INELASTIC DRIFT AMPLIFICATION FACTOR FOR VARIOUS EARTHQUARES

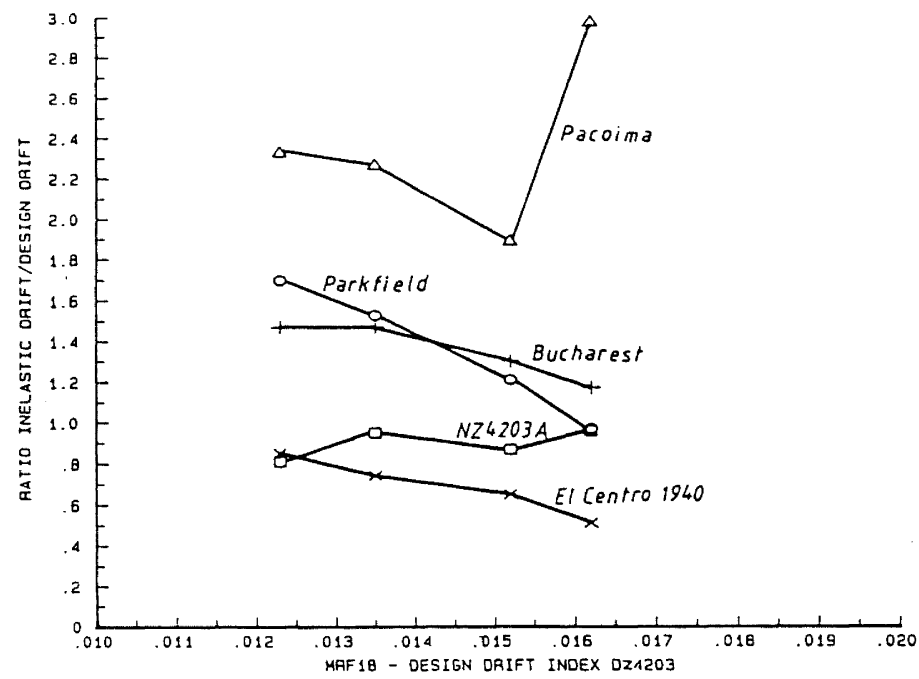

FIGURE 14. EIGHTEEN STOREY FRAMES: INELASTIC DRIFT AMPLIFICATION FACTOR FOR VARIOUS EARTHQUARES 

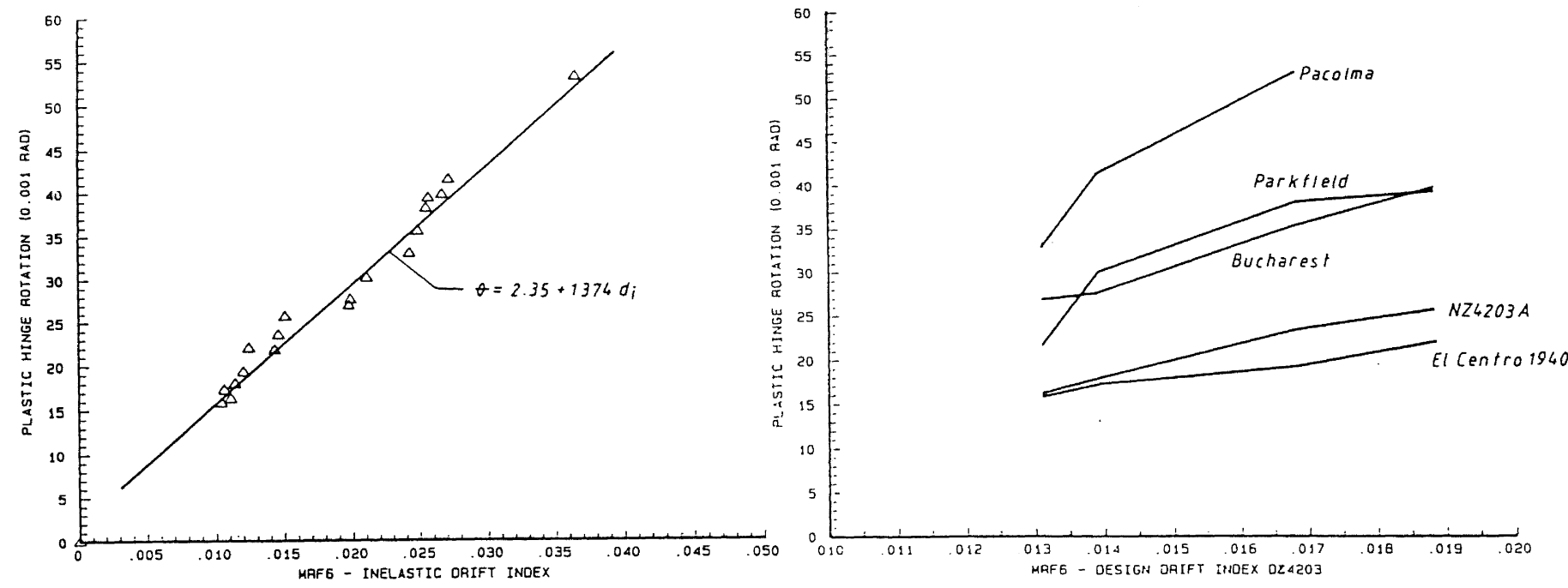

FIGURE 15. SIX STOREY FRAMES: RELATIONSHIP

FIGURE 16. SIX STOREY FRAMES: RELATIONSHIP BETWEEN BEAM PLASTIC HINGE ROTATION AND INELASTIC DRIFT FOR
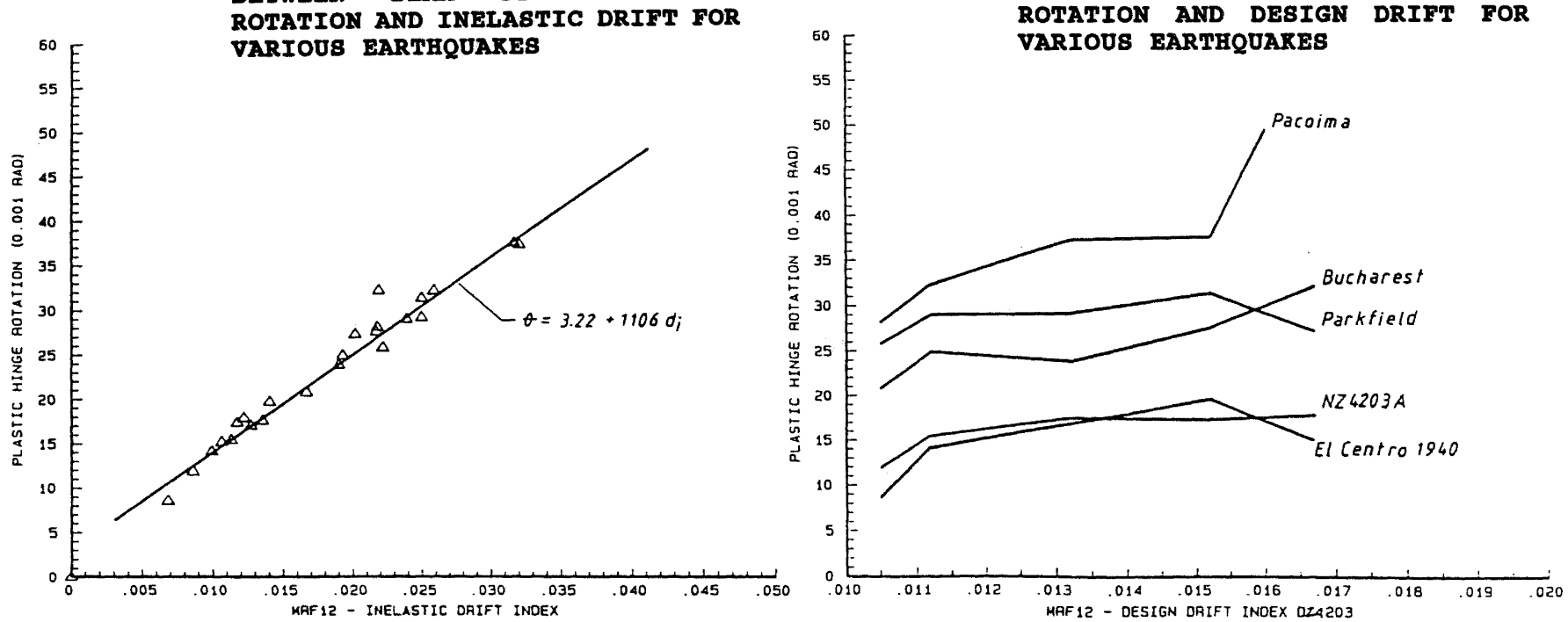

FIGURE 17. TWELVE STOREY FRAMES: RELATIONSHIP BETWEEN BEAM PLABTIC HINGE ROTATION AND INELASTIC DRIFT FOR VARIOUS
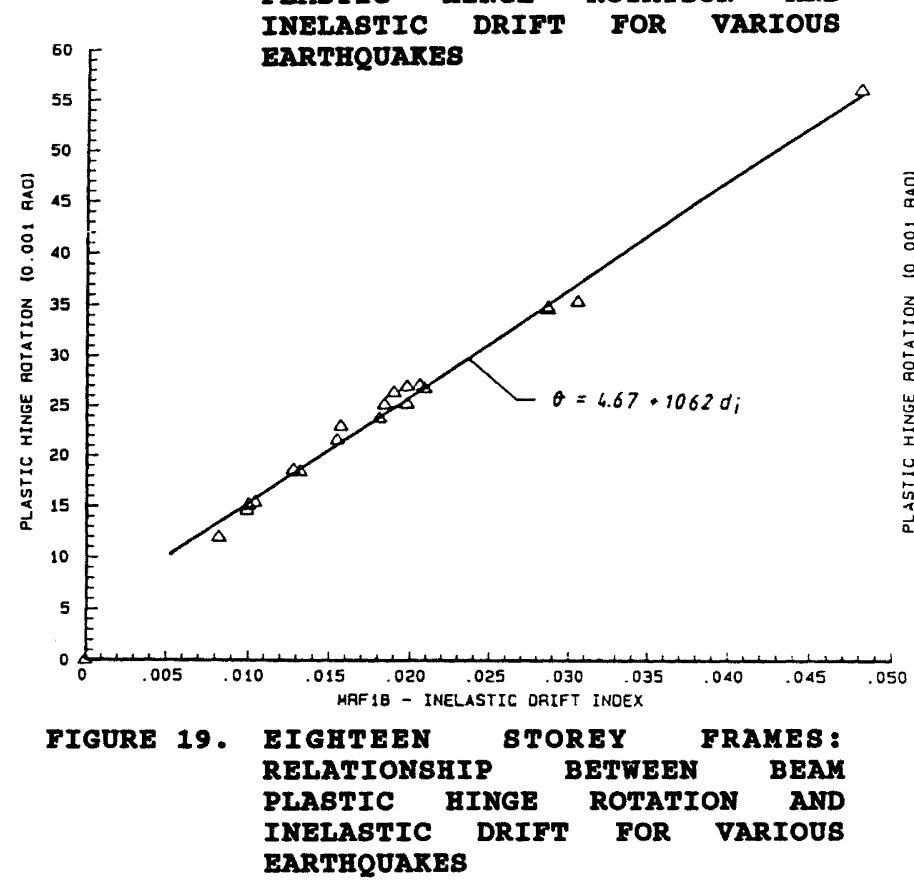

FIGURE 18. TWELVE STOREY FRAMES: RELATIONSHIP BETWEEN BEAY PLASTIC HINGE ROTATION AND DESIGN DRIFT FOR VARIOUS

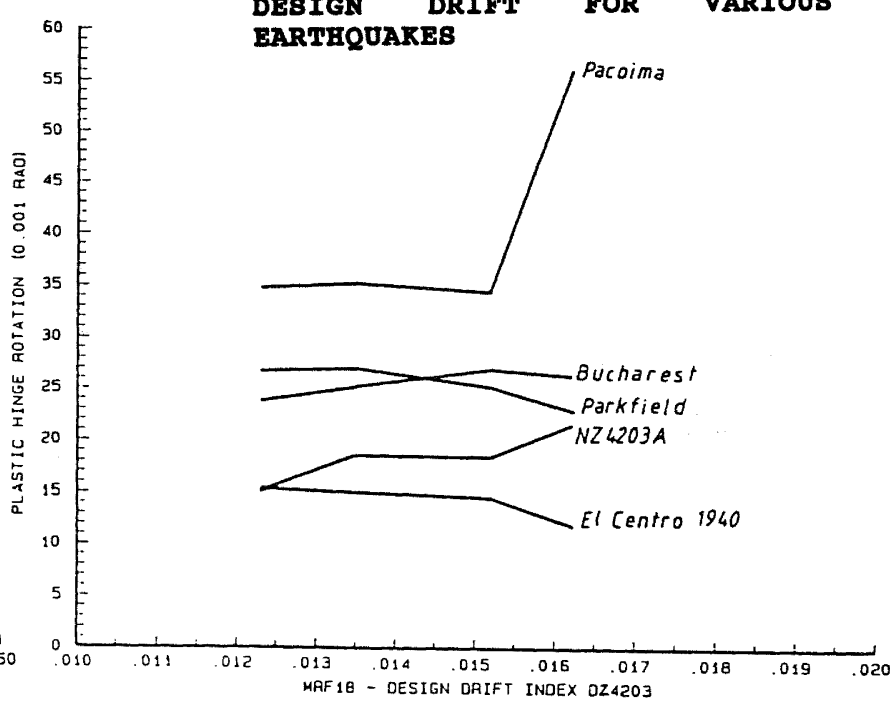

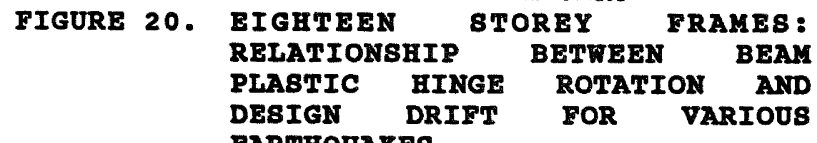
EARTHQUARES 
earthquakes decreased when the design drift indices increased or the frames become more flexible, as shown in Fig. 14. A large amplification factor occured for the design drift index of 0.0162 under the Pacoima Dam record. The Artificial NZ4203/A record showed a slight increase of amplification factor with the increase of the design drift index.

\section{Relationship Between Inter-storey Drift and Plastic Hinge Rotation}

\section{(a) 6 storey frames}

The plot of the values of maximum plastic hinge rotation in the beams for various design drifts and earthquakes show a reasonably linear relationship with maximum inelastic drift index (see Fig. 15). Based on a simple linear regression analysis the relationship can be expressed by the following equation:

$$
\phi=2.35+1374 d_{i}
$$

where $\phi$ is the plastic hinge rotation $(0.001 \mathrm{Rad})$, and $d_{i}$ is the inelastic drift index.

The correlation coefficient for that relationship is 0.988 .

If the limit of plastic hinge rotation is taken as 0.030 radians, the equation above will give a prediction of inelastic drift of 0.020 storey height, obtained from Fig. 15. Under the El Centro 1940 and Artificial NZ4203/A records, Frame no.4 with design drift of $0.0188 \mathrm{~h}$ never achieves the plastic hinge limit of 0.030 radians (Fig. 16). However under Bucharest and Parkfield records this frame achieves the above limit at a design drift of $0.015 \mathrm{~h}$, and at a design drift of $0.013 \mathrm{~h}$ under Pacoima Dam record.

\section{(b) 12 storey frames}

In Fig. 17, the El Centro 1940, Artificial NZ4203/A and Parkfield earthquakes showed little variation in the relationship between design drift DZ4203 and plastic hinge rotation. The Bucharest earthquake gave a small increase for design drifts above $0.0132 \mathrm{~h}$ and the Pacoima Dam earthquake showed a significant increase at a design drift greater than $0.0152 \mathrm{~h}$.

The value of maximum plastic hinge rotation during the El Centro 1940 and Artificial NZ4203/A earthquakes were between 0.010 0.017 radians for these twelve-storey frames and indicated that there should not be a problem for serviceability within these levels of earthquake excitations. Maximum plastic hinge rotation of 0.025 radians occured under Parkfield and Bucharest earthquakes. Pacoima Dam earthquake gave maximum plastic hinge rotation of 0.030 radians at a design drift index of 0.0105 . and excessive plastic hinge rotation occured for a design drift index greater than 0.0152 .

The relationship between plastic hinge rotation and inelastic drift index for the twelve-storey frames was reasonably linear. By simple linear regression, the relationship is given in the following expression:

$$
\phi=3.22+1106 \mathrm{~d}_{\mathrm{i}}
$$

where $\phi=$ plastic hinge rotation $(0.001 \mathrm{rad})$ and $d_{i}=$ the inelastic drift index.

The correlation coefficient for the above equation is 0.984 and the slope of the line from the equation above is close to the slope for the six-storey frames, indicating a relationship independent of the number of the storeys. Fig. 18 shows that a maximum inelastic drift index of 0.025 occurs for a plastic hinge rotation of 0.030 radians. For example, if the limiting maximum plastic hinge rotation of 0.030 radians is expected under Pacoima Dam earthquake, then take the design inelastic drift index to be 0.025 (from Fig. 18), divide by the amplification factor of approximately 2.5 obtained from Fig. 13 for the Pacoima Dam earthquake, and the result is a design drift index limit of 0.010 , based on DZ4203.

\section{(c) 18 storey frames}

The value of maximum plastic hinge rotation as was mentioned earlier was lower than 0.030 radians for all the earthquakes used except Pacoima Dam (see Fig. 19).

The value of maximum plastic hinge rotation during the El Centro 1940 earthquake was 0.015 radians and decreased slightly to 0.012 radians with lower drift indices. The Artificial NZ4203/A record showed 0.015 to 0.022 radians and the value for the Bucharest and Parkfield earthquake was approximately 0.026 radians.

Fig. 20 shows the relationship between maximum plastic hinge rotation and inelastic drift index as follows:

$$
\phi=4.67+1062 \mathrm{~d}
$$

where $\phi=$ plastic hinge rotation $(0.001$ rad), and $d_{i}=$ inelastic drift index.

The correlation coefficient of 0.996 was obtained and the slope of this line was close to the slopes of the twelve and sixstorey frames.

\section{DISCUSSION}

\section{Drift control}

Increasing the beam stiffness is more effective than increasing the column stiffness provided that the column member forces do not result in instability. However, increasing the beam stiffness must be kept in proportion with increasing the column stiffness.

Other ways of controlling the frame lateral stiffness would be to use braced members or steel structural wall systems to provide the sufficient lateral stiffness without increasing the moment capacity of the columns. Braced members are normally used in the minor axis only, but could also be developed to control the drift in the major axis direction. The concrete structural wall is obviously efficient at controlling drift and a steel shear wall should also be so. 


\section{Drift Index Limit}

The existing code [9] limits the interstorey deflections to be not greater than 0.010 of the storey height multiplied by 1 , $5 / 6$ and $2 / 3$ for seismic zones $A, B$ and $C$ respectively. The limit of 0.010 is intended to control the $\mathrm{P}-\Delta$ effect in seismic zone $\mathrm{A}$. To obtain the same control of P- $\Delta$ effects in the other zones so that the generated member forces have the same relativity to the primary seismic member forces as they have in zone $A$, it is necessary to introduce zone factors in the determination of drift (or slope) limits.

The Draft Code [10] suggests the limit of horizontal inter-storey deflection to be the value of $\mathrm{Z} / 50$ times the difference in elevations of those levels, where $\mathrm{Z}$ equals 0.85 for Wellington (in the seismic zone $A$ of the existing code [9]), 0.65 for Christchurch (previously zone B) and 0.5 for Auckland (previously zone $\mathrm{C}$ ). The inclusion of the zone factor ensures that the ratio of $\mathrm{P}-\Delta$ moment to total moment at any level is independent of the geographic location of the structure. Overall building rotation is included in the inter-storey deflection.

The results for the six-storey frames show that the limit for the EI Centro 1940 earthquake could be increased to $0.019 \mathrm{~h}$ and still keep the maximum beam plastic hinge rotation under 0.030 radians. If suitable behaviour under a severe earthquake, i.e. the Pacoima Dam earthquake, is such that there is to be a negligible $P-\Delta$ effect, the drift limit would need to be reduced to $0.013 \mathrm{~h}$ for the six-storey frames.

The drift limit in the six-storey frame can be taken as 1.1 times the drift limit in the taller structures.

In the investigation of the twelve-storey moment resisting frames the drift limit of $0.011 \mathrm{~h}$ almost allowed the limit of plastic hinge rotation for the Pacoima Dam earthquake to be reached. This limit is conservative for the New Zealand code design earthquake. Under El Centro 1940, a drift limit of $0.017 \mathrm{~h}$ was still acceptable without significant $P-\Delta$ effects.

In the eighteen-storey frames, drift limits of less than $0.012 \mathrm{~h}$ gave satisfactory behaviour under the Pacoima Dam earthquake. Under the EI Centro 1940 earthquake this limit could be raised to $0.017 \mathrm{~h}$ as is the limit in the twelve-storey frame.

\section{Plastic Hinge Rotation}

The maximum plastic hinge rotation for the frame with a design drift limit of $0.017 \mathrm{~h}$ never exceeded 0.030 radians during the $\mathrm{El}$ Centro 1940 earthquake. The drift limit of $0.017 \mathrm{~h}$ discussed above gives rise to a maximum plastic hinge rotation of 0.020 radians under the EI Centro 1940 earthquake.

The upper limit for the possible plastic hinge rotations that occurred under different earthquake records can be seen in Fig. 21. The data was taken from all the P-A analyses of the six, twelve and eighteenstorey frames used in this study. A linear line gives a good approximation for the prediction of maximum plastic hinge rotation under different earthquakes based on the design drift (DZ4203).

The inelastic drift index and plastic hinge rotation relationship is independent of the design drift index or earthquake levels, and P- $\Delta$ effects can be tolerated when the inelastic drift is between $0.020-0.025$ times the storey height. The investigation outlined above gives a very close curve from linear regression, as is shown in Fig. 22. The data from all the frames result in a linear fit as shown in Fig. 23 with the following expression:

$$
\phi=3.60+1165 \mathrm{~d}_{i}
$$

where $\phi=$ the plastic hinge rotation 10.001 $\mathrm{rad}$, and $d_{i}=$ the inelastic drift index.

The correlation coefficient is 0.966 and from the above expression a plastic hinge rotation of 0.030 radians will limit the inelastic drift to 0.023 times the storey height.

\section{Displacement Magnification Factor}

The conversion of the inter-storey drift, from the design drift based on the draft code ( $D Z 4203)$ to the inelastic inter-storey drift can be done by using an approximate drift amplification factor as is given in Table 2 .

In this study a displacement ductility factor of 3.00 was used as a displacement magnification factor. This is correct when the equal displacement theory is satisfied such as for the EI Centro 1940 earthquake. The average displacement amplification factor of 0.82 for the design drift is adequate. This value is the same as 2.46 times the drift from the equivalent static analysis. The displacement amplification above relates to the intensity of the earthquakes. The amplification factor for the El Centro 1940 earthquake shows that this earthquake is less strong than the DZ4203 design level earthquake.

\section{significance of $P-\Delta$}

The effect of P- $\Delta$ was small for the "design" level earthquakes of EI Centro 1940 and the Artificial NZ4203/A. The effect was greater for a much stronger earthquake such as the Pacoima Dam excitation, though many of the structures investigated would undergo excessive deformation and possible collapse under this earthquake. While there could be some relaxation of the current code drift limits in relation to design level earthquakes, their retention at the present levels appears to ensure that $P-\Delta$ effects will be reasonably small when the structures are subjected to larger, but less likely, earthquakes.

\section{ACKNOWLEDGEMENTS}

The study presented in this project was carried out in the Department of Civil Engineering, University of Canterbury, under the overall guidance of it's Head, Professor 


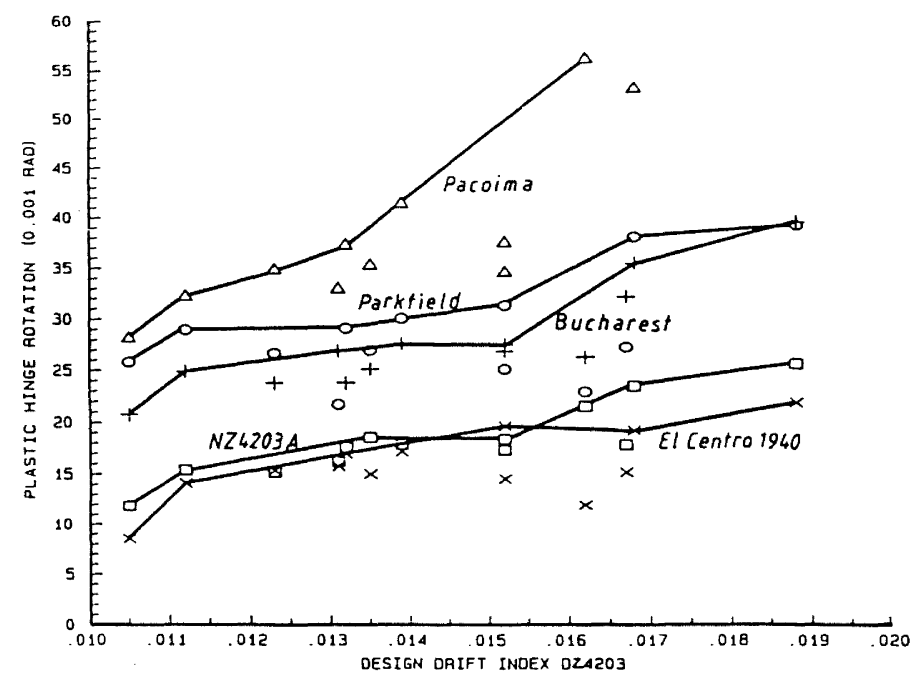

FIGURE 21. PREDICTION OF PLASTIC HINGE ROTATION BASED ON THE DESIGN DRIFT INDEX OF DZ4203

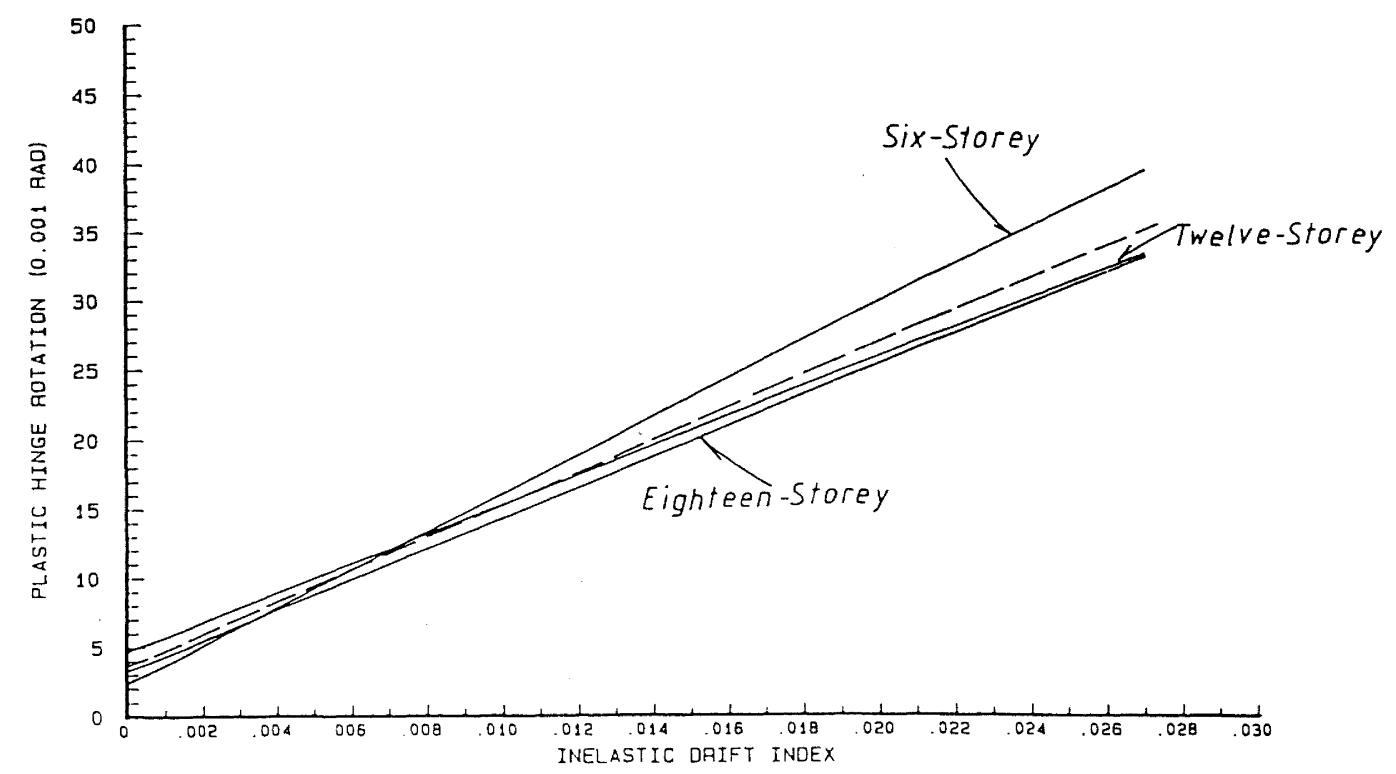

FIGURE 22. RELATIONSHIP BETWEEN BEAM PLASTIC HINGE ROTATION AND INELASTIC DRIFT INDEX

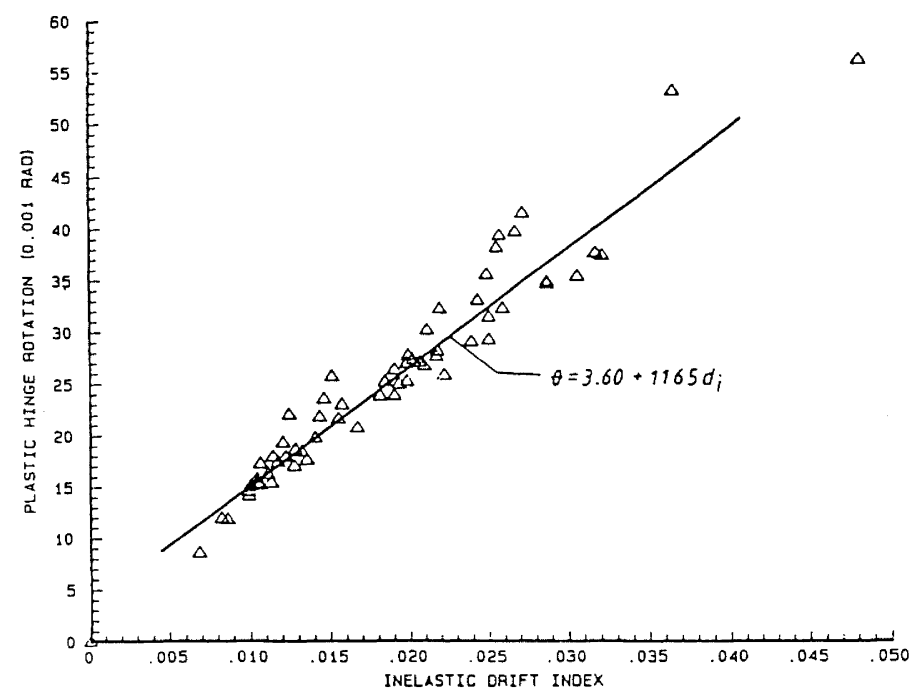

FIGURE 23. PREDICTION OF PLASTIC HINGE ROTATION BASED ON THE INELASTIC DRIFT INDEX 
TABLE 2 DISPLACEMENT MAGNIFICATION FACTOR

\begin{tabular}{|c|c|c|c|c|}
\hline \multirow[t]{2}{*}{ Earthquake } & \multicolumn{3}{|c|}{ number of stories } & \multirow{2}{*}{$\begin{array}{c}\text { average } \\
\text { amplification }\end{array}$} \\
\hline & $\operatorname{six}$ & twelve & eighteen & \\
\hline $\begin{array}{l}\text { 1. Bucharest } \\
\text { 2. El Centro } 1940 \\
\text { 3. Art. NZ4203/A } \\
\text { 4. Pacoima Dam } \\
\text { 5. Parkfield }\end{array}$ & $\begin{array}{l}1.50 \\
0.80 \\
0.85 \\
2.20 \\
1.50\end{array}$ & $\begin{array}{l}1.60 \\
0.85 \\
1.00 \\
2.40 \\
2.00\end{array}$ & $\begin{array}{l}1.40 \\
0.80 \\
1.00 \\
2.30 \\
1.60\end{array}$ & $\begin{array}{l}1.50 \\
0.82 \\
0.95 \\
2.30 \\
1.70\end{array}$ \\
\hline
\end{tabular}

\section{R. Park.}

The project financial assistance provided by Heavy Engineering Research Association, New Zealand is also gratefully acknowledged.

The first named author would gratefully thank Parahyangan Catholic University, Bandung, Indonesia for the financial support which enabled him to study in New Zealand.

\section{REFERENCES}

1. ANDREWS, A.L." "Slenderness Effects in Earthquake Resisting Frames", Bulletin of The New Zealand National society for Earthquake Engineering, Vol.10, No.3, September 1977 .

2. BUTTERWORTH, J.W., SPRING, K.C.F., "Column Design ", Section D, New Zealand steel study Group, Bulletin of The New Zealand National Society for Earthquake Engineering, Vol.18, No.4, December 1985.

3. CARR,A.J., MOSS,P.J., "The Effects of Large Displacements on The Earthquake Response of Tall Concrete Frame structures" Bulletin of The New Zealand National society for Earthquake Engineering, Vol.13, No.4, December 1980.

4. De BUEN, 0., "Chapter 4, Steel Structures" in "Design of Earthquake Resistant Structures", ed. E.Rosenblueth, Pentech Press, Plymouth, England, 1980.

5. LUKEY, A.F., ADAMS, P.F., "Rotation Capacity of Beams Under Moment Gradient" Journal ASCE, ST6, June 1969.

6. MONTGOMERY,C.J., "Influence of P-Delta Effects on Seismic Design", Canadian Journal of Civil Engineering, No.8, 1981.

7. MOSS, P.J., CARR, A.J., BUCHANAN, A.H., "Seismic Response of Low Rise Buildings 1. Research Report No.86-15, Department of Civil Engineering, University of Canterbury, June 1986 .
8. NEW ZEALAND STANDARD: "Code for Design of Steel structures", NZ3404, 1977.

9. NEW ZEALAND STANDARD: "Code of Practice for General structural Design and Design Loadings for Buildings", NZS4203, 1984.

10. NEW ZEALAND STANDARD: "General structural Design and Design Loadings for Buildings", Draft for Comment, DZ4203, (being a revision of Reference 9), May 1986 .

11. OTANI,S., "Hysteresis Models of Reinforced Concrete for Earthquake Response Analysis", Journal of The Faculty of Engineering, The University of Tokyo (B), Vol.XXXVI, No.2 (1981).

12. PAULAY,T., "A Consideration of P-Delta Effects in Ductile Reinforced concrete Frames", Bulletin of The New Zealand National Society for Earthquake Engineering, Vol.11, No.3, September 1978 .

13. TJONDRO, J.A., "Analytical Investigation of P-Delta Effects in Medium Height Moment-Resisting steel Frames Under Seismic Loading", M.E. Report, Department of Civil Engineering, University of Canterbury, February 1988. (An edited version of this Report was published as Civil Engineering Research Report 88/13, December 1988 authored by Tjondro, Moss and Carr).

14. TJONDRO, J.A., MOSS,P.J. and CARR, A.J. "Seismic P-Delta Effects in Medium Height Moment-Resisting Steel Frames" submitted to the Journal of Engineering Structures, 1990 .

15. WALPOLE, W.R., BUTCHER, G.W., "Beam Design", Section C, New Zealand steel study Group, Bulletin of The New Zealand National Society for Earthquake Engineering, Vol.18, No.4, December 1985. 